\title{
Corrosion Inhibition of Mild Steel with Tolyltriazole
}

\author{
H. E. Fathabadi ${ }^{a}$ (D), M. Ghorbani ${ }^{b^{*}}$, H. Mokarami Ghartavol ${ }^{b}$ \\ ${ }^{a}$ Sharif University of Technology, Materials Science and Engineering Department, International
Campus, Kish Island, Iran.
${ }^{b}$ Sharif University of technology, Materials science and Engineering Department, Tehran, Iran.
}

Received: August 30, 2020; Revised: March 3, 2021; Accepted: April 6, 2021

\begin{abstract}
Tolyltriazole (TTA) is a well-defined corrosion inhibitor for copper and copper alloys. However, there is little literature about its corrosion inhibition performance for mild steels in corrosive environments. This paper studied the electrochemical behavior of TTA in $0.5 \mathrm{M} \mathrm{HCl}$ solutions. Also, the morphology and nature of TTA layers on the steel surface were investigated. Electrochemical results showed that TTA is an excellent corrosion inhibitor for mild steel in acidic media with an efficiency of $91 \%$ for $0.07 \mathrm{M}$ concentration. The results also indicated that TTA is a mixed-type inhibitor. XRD analysis revealed that the inhibition mechanism of TTA is based on the formation of an organic film due to the physically adsorbed molecules of TTA. AFM and EDS results showed that the formed layers decrease the adsorptivity of corrosive elements $\left(\mathrm{Cl}^{-}\right)$on the steel surface. Density Functional Theory (DFT) study confirmed the experimental results.
\end{abstract}

Keywords: Tolyltriazole (TTA), mild steel, corrosion inhibitor, Electrochemical, morphology, acidic media.

\section{Introduction}

Mild steels are frequently used to manufacture different equipment in variety of industries. Although mild steels economical and have suitable mechanical properties in many industrial applications, they are prone to the corrosion. One of the most effective approaches to avoid corrosion in closed systems is the addition of corrosion inhibitors to corrosive solutions. A variety of organic inhibitors provide a possibility for the application of economical metals in different industries for corrosive environments ${ }^{1-4}$.

As widely applicable organic corrosion inhibitors, azoles derivatives have various applications in the industries of copper $^{5-8}$, aluminum ${ }^{9-11}$ and their alloys with the exposure to corrosive medium. Azoles derivatives can be applied for a wide range of steels ${ }^{12-14}$ in acidic or alkaline solutions along with chloride ions. Among the group of azole derivatives, Tolyltriazole (TTA, $\mathrm{C}_{7} \mathrm{H}_{7} \mathrm{~N}_{3}$, with a chemical structure given in Figure $1^{5}$ ) is the most widely used corrosion inhibitor for copper and copper alloys, in cooling water systems, because of its low cost and high performance in corrosion inhibition ${ }^{5,7,15-22}$.

Derived from benzotriazole (BTA), TTA has an additional methyl group which is connected to the benzene ring. Therefore, TTA is a mixture of 4- and 5-methyl- $1 \mathrm{H}-$ benzotriazole. Hydrophobic properties of the methyl branch, which is connected to the benzene ring, lead to the better performance of TTA in corrosion inhibition of copper and copper alloys $\mathrm{s}^{6,23,24}$. Although corrosion inhibition behavior of Tolyltriazole is reportedly similar to BTA, but there is little data on its detailed performance of corrosion inhibition ${ }^{25}$.

*e-mail: ghorbani@sharif.edu
Formation of a protective polymeric film, $\mathrm{Cu}$ (I)-TTA by the chemical adsorption of TTA on copper surface is accounted as the corrosion inhibition mechanism of $\mathrm{TTA}^{23,26}$. The triazole groups are bonded to copper atoms via chemisorption of non-bonding electrons of nitrogen atoms. The molar ratio of $1: 1$ for TTA to $\mathrm{Cu}$ is accepted in the adsorbed layer ${ }^{6,23,27,28}$.

Although corrosion inhibition properties and mechanisms of TTA on copper alloys have been investigated in numerous research, there is little published data about its effect on corrosion behavior of mild steel specially for API 5L steel pipelines as one of the most useful type in oil and gas industry. Three complexes of benzimidazoles were synthesized by Yadav et al. ${ }^{29}$ as corrosion inhibitors of mild steels in $15 \%$ $\mathrm{HCl}$ solutions and an increase in corrosion resistance was observed through the gradual enhancement of concentrations. Different concentrations of BTA, benzimidazole, and imidazole in alkaline water were considered by Subramanyam and Mayanna $^{30}$ with the maximum inhibition efficiency for imidazole. Feng et. al. studied BTA for X65 steel pipeline in $0.01 \mathrm{M} \mathrm{NaHCO}_{3}$ solution. The results showed that BTA is a very effective corrosion inhibitor for X65 in this media by the efficiency of $95 \%$, but the adsorption mechanism and temperature effects were not investigated in their work ${ }^{31}$.

The current paper has focused on the investigation of corrosion inhibition efficiency of TTA for API 5L Grade $\mathrm{B}$ mild steel in hydrochloric acid solutions. In this regard, possible mechanisms of corrosion inhibition and the nature of the adsorbed TTA molecules are discussed in details using the achieved results from electrochemical measurements, Adsorption isotherm analysis, topographical and Density 
$\mathrm{CH}_{3}$

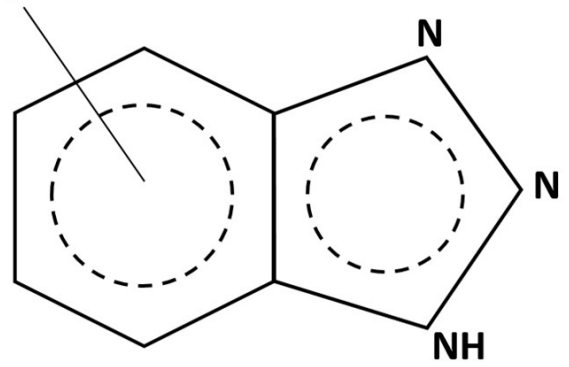

Figure 1. Chemical structure of Tolyltriazole (TTA)

Functional Theory (DFT) studies. To the best of our knowledge there is no published data on DFT study of TTA corrosion inhibition on metal surface.

\section{Experimental}

\subsection{Preparation of the specimens and solutions}

API 5L Grade B pipeline, with a chemical composition (wt.\%) of C $0.13 \%$, Si $0.22 \%$, Mn 1.0\%, P $0.008 \%$, S $0.005 \%$, $\mathrm{Cu} 0.1 \%$, Mo $0.01 \%$ and $\mathrm{Fe}$ balance were applied as low carbon steel substrates. The specimens were cut and then they were coated by a cold-curing epoxy resin to provide a $10 \mathrm{~mm} \times 10 \mathrm{~mm}$ area for exposure. Work surfaces of the steel samples were abraded using $\mathrm{SiC}$ emery papers from 60 to 1200 grit size. Finally, the samples were rinsed with deionized water and they were degreased in ethanol (purity of $99.5 \%$ ) and acetone (purity of $99+\%$ ). Then the specimen were air-dried and they were located in a desiccator before experiments. To minimize the effects of surface roughness of metal for atomic force microscopy (AFM), specimens were abraded up to 1500 grit with SiC emery paper, and then they were polished with a suspension of $1 \mu \mathrm{m}$ diamonds. Then the samples were rinsed with deionized water and degreased in ethanol and acetone, and finally they were air-dried. The solutions of $0.5 \mathrm{M}$ Hydrochloric acid were prepared using $37 \% \mathrm{HCl}$ (Merck) and they were diluted using deionized water. Tolyltriazole (99.0\% SAMCHUN, South Korea) was added to the solutions with different concentrations $(0,0.01$, $0.03,0.05$ and $0.07 \mathrm{M}$ ). The solutions were stirred for $2 \mathrm{~h}$.

\subsection{Electrochemical studies}

Electrochemical properties were determined using Autolab $302 \mathrm{~N}$ potentiostat/galvanostat (Switzerland) equipped with Nova 1.11 software. The counter electrode was a Platinum plate with dimensions of $3 \times 1 \mathrm{~cm}$. Potentials were recorded according to the saturated calomel electrode (SCE). The distance between the counter and working electrodes was $2 \mathrm{~cm}$. Initially, for investigation of the solution stabilization process, the open circuit potential (OCP) was plotted versus time. Then, the potentiostatic polarization curves were drawn using potential range of -250 to $+250 \mathrm{mV}$ (vs. OCP) and potential scanning rate of $1 \mathrm{mV} / \mathrm{s} 40$ minutes after stabilization of $\mathrm{HCl}$ solutions. Polarization tests were conducted on the solutions with different concentrations ( 0 to 0.07 M TTA $)$ at various temperatures $(293,303,313$ and $323 \mathrm{~K})$. The electrochemical corrosion parameters, which were determined using polarization curves, included corrosion potential $\left(\mathrm{E}_{\text {corr }}\right)$, corrosion current density $\left(\mathrm{i}_{\text {corr }}\right)$, cathodic Tafel slope $\left(\beta_{\mathrm{c}}\right)$, and anodic Tafel slope $\left(\beta_{\mathrm{a}}\right)$. EIS measurements were also performed on the steel electrode after 40 minutes of being dipped into the solutions with a frequency range of $100 \mathrm{~Hz}$ to $0.01 \mathrm{~Hz}$ at Open Circuit Potential (OCP) with a small AC amplitude voltage of $10 \mathrm{mV}$.

\subsection{Surface analysis: SEM/EDS/AFM/XRD}

To evaluate the effects of adsorption of TTA molecules on inhibition of metal corrosion, the exposed surfaces of metal were investigated in terms of morphology and structural properties. Scanning electron microscopy (Phenom ProX Desktop SEM) was applied to study the exposed metal surfaces after being immersed for $2 \mathrm{~h}$ in $0.5 \mathrm{ml} \mathrm{HCl}$ solutions containing 0, 0.01, 0.03, 0.05 and $0.07 \mathrm{M}$ of TTA.

Energy-dispersive X-ray spectroscopy (EDS) analysis was done by FESEM TESCAN MIRA III with SAMX detector. Atomic force microscopy (NTEGRAAFM NT - MDT) was conducted on steel electrodes after 8 hours of immersion in the solutions containing various concentrations of TTA. The silicon tip of AFM tip was mounted on triangular cantilevers $(450 \mu \mathrm{m} \times 50 \mu \mathrm{m} \times 2 \mu \mathrm{m})$ with an average spring constant of $0.02 \sim 0.77 \mathrm{~N} / \mathrm{m}$. The scanning process was configured as a contact model, with a scanning rate of $1 \mathrm{~Hz}$ in the scanning rang of $10 \mu \mathrm{m} \times 10 \mu \mathrm{m}$, and a resolution of $256 \times 256$ pixels. X-ray diffraction technique (Diffractometer system XPERT-PRO ,2500 V) was applied to investigate the effects of inhibitor films on the crystalline phases of the steel surface with $\mathrm{Cu}-\mathrm{K} \alpha$ radiation generated at $40 \mathrm{kV}$ and $40 \mathrm{~mA}$, a scanning range of $10^{\circ}$ to $90^{\circ}$ and a step size of $0.026^{\circ}$.

\subsection{Density-functional theory (DFT) study}

The effectiveness of an inhibitor is related to its spatial structure as well as its molecular electronic structure. In this regard, quantum and theoretical chemistry have proved to be a powerful tool for studying corrosion inhibition mechanism. Proper models with computational simulations based on quantum and chemistry can support and confirm experimental findings; also by prediction of complicated physicochemical phenomena can decrease the costs and labors for experimental measurements. Corrosion inhibition is affected by the nature and state of the metal surface, corrosive environments, the chemical structure of inhibitors and their adsorption efficiencies onto the surface. Researches showed that molecular orbital energies, frontier orbital energy gap; $\mathrm{E}_{\text {номо }}-\mathrm{E}_{\text {LUмо }}$ (where HOMO is the highest occupied molecular orbital and LUMO is the lowest unoccupied molecular orbital), atomic charges, and dipole moments are the most important parameters in corrosion inhibition studies ${ }^{32-35}$.

DFT is based on the fact that the thermodynamic ground states of both molecules and materials include the distribution of electrons which are in equilibrium with a field of positively charged point nuclei. Since the mass of nuclei is much higher than an electron, the electronic relaxation is much faster than the motion of the nucleus and the calculation of atomic nuclei motion and electrons motion can be done separately. When the positions of the nuclei change, the electronic distribution also shifts in such a way 
as to minimize the total system energy. DFT can simulate the electronic structure of molecules or materials, therefore, should be considered among the most useful techniques to predict the thermodynamic and kinetic properties of corrosion inhibition ${ }^{36}$. Due to its theoretical-based work, DFT has been widely accepted as a "green corrosion inhibition technique" and it can be used to design corrosion inhibitors to prevent corrosion $^{37}$. Moreover, by using sophisticated computational tools, reactivity behavior in terms of hard and soft acid/base (HSAB) theory can be studied that provides a systematic way for analyzing and predicting inhibitor/surface interaction ${ }^{38}$.

In the DFT calculations, for the first step the geometry of the inhibitors was fully optimized and vibrational analysis was performed simultaneously in the gas phase without any symmetry constraints by using PBE0/6-31G(d,p) as the method of theory. The resulting geometry was checked with respect to being at global minimum on the potential energy surface, as shown by the absence of imaginary frequencies. All calculations were performed with the ORCA 4.2.1 package of programs.

\section{Results and Discussion}

\subsection{Open circuit potential (OCP) curves}

OCP versus immersion time curves of steel electrodes in $\mathrm{HCl}$ solutions containing different concentrations ( 0 to $0.07 \mathrm{M}$ ) of Tolyltriazole (TTA) are indicated in Figure 2. Generally, addition of TTA into $\mathrm{HCl}$ solutions leads to the OCP shifts to more positive potentials. In an uninhibited solution $(0.0 \mathrm{M}$ TTA), the OCP establishes quickly at $-0.55 \mathrm{~V}_{\text {SCE }}$ after about 15 minutes of immersion. Addition of TTA results in the shifts of OCP curves to more noble potentials. Consequently interactions of inhibitors on the surface of steel and also formation of possible protective layers lead to the prolongation of the time required for stabilization. Considering the dependence on inhibitor concentration OCP is estimated to be established after 30 to $40 \mathrm{~min}$. Therefore, the duration of $40 \mathrm{~min}$ is chosen as the stabilization time for subsequent electrochemical measurements. Takenori et.al did polarization tests for TTA and some other derivatives of BTA after $10 \mathrm{~min}$ immersion in the $3 \% \mathrm{NaCl}$ solution for Iron substrate ${ }^{39}$.

As increase of TTA concentrations lead to the OCP shifts to more noble potentials, its reason might be attributed to the inhibiting effects of TTA on steel oxidation and evolution of hydrogen gas in acidic solutions in which TTA is preferably adsorbed on anodic and cathodic sites of the steel. The delay of steel surface anodic reactions under open circuit conditions is believed to be the reason for OCP displacement to more noble potentials ${ }^{40}$. Consequently there is a little displacement in OCP due to inhibitor inclusion with the maximum level of about $70 \mathrm{mV}$ (from $-0.55 \mathrm{~V}_{\mathrm{SCE}}$ for uninhibited solution to $-0.48 \mathrm{~V}_{\mathrm{SCE}}$ for $0.07 \mathrm{M}$ TTA) which confirms the mixed-type behavior of TTA as an inhibitor.

\subsection{Potantiostatic polarization measurements}

\subsubsection{Effect of inhibitor concentration}

Figure 3 shows the Potentiostatic polarization curves of mild steel in $0.5 \mathrm{M} \mathrm{HCl}$ solution with various concentrations
(0 to $0.07 \mathrm{M}$ ) of TTA. As expected, TTA addition into the solution leads to the enhancement of corrosion potential $\left(\mathrm{E}_{\text {corr }}\right)$ to higher noble potentials. Furthermore, enhancement of TTA concentration results in the shifts of both cathodic and anodic curves to lower current densities. However the effect of TTA inhibition on anodic reactions is more pronounced at a constant potential of the plot and the potential displacement in the anodic branch is much lower than the former. Thus TTA acts as a mixed-type inhibitor which effectively retards both cathodic and anodic reactions on the mild steel surface but its action is more pronounced in the inhibition on anodic reactions. Mahbuboor et. al showed that TTA is mixed behavior type inhibitor for copper ${ }^{5}$.

Dissolution of Fe ions might be the reason for anodic reactions of carbon steel in acidic solutions, while the cathodic reactions are mainly related to the hydrogen evolution.

Table 1 shows the electrochemical corrosion parameters which were obtained from Tafel polarization, including $\mathrm{E}_{\text {corr }}$, corrosion current density $\left(\mathrm{i}_{\text {corr }}\right)$, slopes of the cathodic and anodic branches $\left(\beta_{\mathrm{c}}, \beta_{\mathrm{a}}\right)$, and the inhibition efficiency (IE\%) as a function of TTA concentration. The inhibiting efficiency, IE, can be calculated by Equation 1:

$$
\mathrm{IE} \%=\frac{\mathrm{i}_{\text {corr }}^{0}-\mathrm{i}_{\text {corr }}}{\mathrm{i}_{\text {corr }}^{0}} \times 100 \%
$$

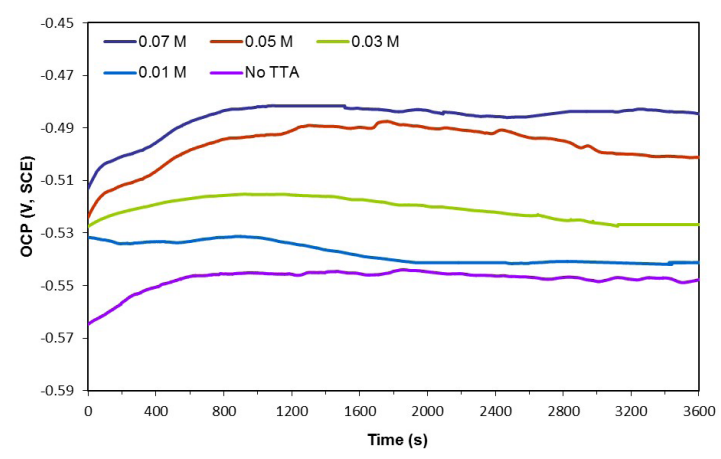

Figure 2. Open circuit potential of mild steel in $0.5 \mathrm{M} \mathrm{HCl}$ solution containing various concentrations of TTA $(0$ to $0.07 \mathrm{M})$ at $293 \mathrm{~K}$ after 3600 s immersion.

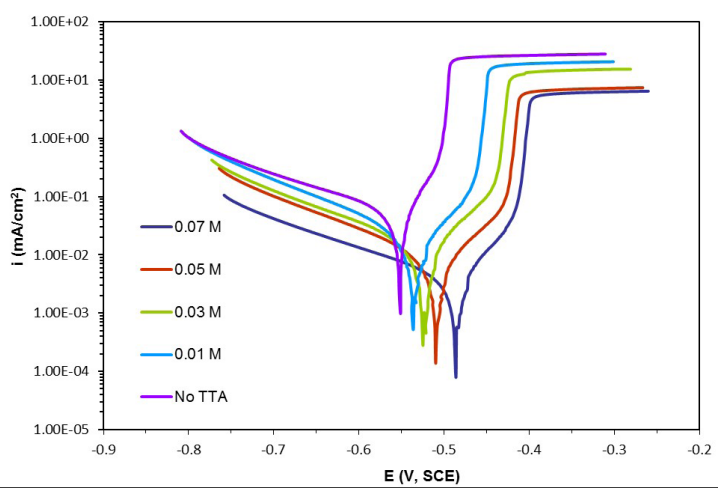

Figure 3. Potentiostatic polarization curves of mild steel in $0.5 \mathrm{M}$ $\mathrm{HCl}$ solution with various concentrations of TTA $(0$ to $0.07 \mathrm{M})$ at room temperature (293 K). 
Table 1. Electrochemical corrosion parameters obtained from the polarization curves of mild steel in $0.5 \mathrm{M} \mathrm{HCl}$ solution with different concentrations of TTA ( 0 to $0.07 \mathrm{M})$.

\begin{tabular}{cccccc}
\hline Concentration $(\mathrm{M})$ & $\mathrm{E}_{\text {corr }}, \mathrm{V}(\mathrm{SCE})$ & $\mathrm{i}_{\text {corr }}, \mathrm{mA} / \mathrm{cm}^{2}$ & $\beta_{\mathrm{a}}, \mathrm{Vdec}^{-1}$ & $\beta_{\mathrm{c}}, \mathrm{Vdec}^{-1}$ & $\mathrm{IE}(\%)$ \\
\hline Blank & -0.551 & 0.00198 & 0.041 & -0.035 & --- \\
\hline 0.01 & -0.535 & 0.00130 & 0.032 & -0.021 & 34.4 \\
\hline 0.03 & -0.524 & 0.00100 & 0.019 & -0.022 & 49.2 \\
\hline 0.05 & -0.522 & 0.00051 & 0.064 & -0.052 & 74.1 \\
\hline 0.07 & -0.486 & 0.00017 & 0.022 & -0.026 & 91.4 \\
\hline
\end{tabular}

Table 2. Corrosion efficiency results of mild steel in $0.5 \mathrm{M} \mathrm{HCl}$ solution with different concentrations of TTA $(0.01$ to $0.07 \mathrm{M})$ at various temperatures $(293,303,313$ and $323 \mathrm{~K})$.

\begin{tabular}{ccccc}
\hline \multirow{2}{*}{ Temperature $(\mathrm{K})$} & \multicolumn{5}{c}{ EI \% } \\
\cline { 2 - 5 } & 0.01 M TTA & 0.03 M TTA & 0.05 M TTA & 0.07 M TTA \\
\hline 293 & 34.4 & 61.9 & 78.1 & 91.4 \\
\hline 303 & 29.4 & 57.0 & 74.1 & 87.3 \\
\hline 313 & 26.5 & 53.4 & 69.0 & 83.3 \\
\hline 323 & 23.1 & 50.9 & 64.5 & 79.2 \\
\hline
\end{tabular}

where $\mathrm{i}_{\text {corr }}^{0}\left(\mathrm{~mA} / \mathrm{cm}^{2}\right)$ and $\mathrm{i}_{\text {corr }}\left(\mathrm{mA} / \mathrm{cm}^{2}\right)$ are corrosion current densities in the absence and presence of the inhibitor in the solution, respectively.

According to the results which indicated the lower rates of corrosion reactions, it can be deduced that corrosion current density decreases significantly with the increase of TTA concentration in $\mathrm{HCl}$ solution. The increase of $\mathrm{E}_{\text {corr }}$ with TTA addition well corresponds to OCP curves. $\mathrm{E}_{\text {corr }}$ displacements are less than $-85 \mathrm{mV}$ (65 $\mathrm{mV}$ maximum here), proving the mixed-behavior of TTA as an inhibitor ${ }^{41}$. Furthermore it is found that the curve slopes ( $\beta_{c}$ and $\beta_{\mathrm{a}}$ ) vary with addition of inhibitor addition which brings about some bigger changes in the anodic branch of the curves $\left(\beta_{\mathrm{a}}\right)$.

The inhibition efficiency, EI\%, increases continuously with the enhancement of TTA concentration. When the TTA concentration is $0.07 \mathrm{M}$, the inhibition efficiency at room temperature $(293 \mathrm{~K})$ is about $91 \%$. No significant change in corrosion current nor efficiency of inhibitor was noted with further addition of TTA.

It is concluded that TTA is an effective corrosion inhibitor for mild steel in chloride acidic media. Further addition of TTA above $0.07 \mathrm{M}$ leads to a relatively stable $i_{\text {corr }}$ which is due to the completion of protective film formation on steel surface.

\subsubsection{Effect of temperature}

The effects of different temperatures $(293,303,313$ and $323 \mathrm{~K}$ ) on corrosion behavior of mild steels in $\mathrm{HCl}$ solution were clarified with and without varied concentrations of TTA. The results of polarization analysis indicating the influence of temperature on corrosion inhibition are represented in Figure 4. The relating temperature and EI\% for different concentrations of TTA are listed in Table 2. As it was expected, temperature enhancement leads to the gradual decrease of efficiency of corrosion inhibition as it reaches to $79 \%$ at $323 \mathrm{~K}$ for $0.07 \mathrm{M}$ TTA. Reduction of inhibition efficiency with temperature is caused by enhancement of carbon steel dissolution and also partial desorption of TTA layer off the metal surface. The observed relationship between EI\% and

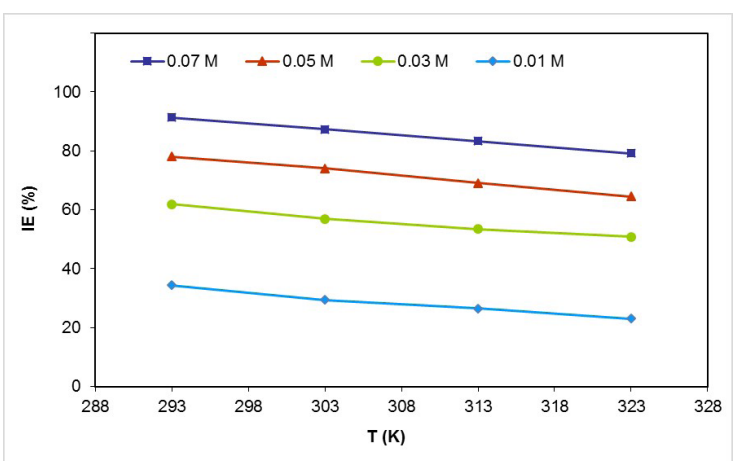

Figure 4. Effect of temperature on inhibition efficiency of TTA with different concentrations $(0.01$ to $0.07 \mathrm{M})$ on mild steel in $\mathrm{HCl}$ solution at various temperatures (293, 303, 313 and $323 \mathrm{~K})$.

temperature demonstrates the effective role of TTA as an effective inhibitor at higher temperatures (293 to $323 \mathrm{~K}$ here).

Also inhibition efficiency reduction with increase in temperature, may be due to possible repulsion of some of the adsorbed TTA from the metal surface at higher temperatures. This behavior shows that TTA were physically adsorbed on the steel surface ${ }^{42}$.

\subsubsection{Adsorption isotherm and thermodynamic parameters}

To describe the probable mechanism for the interaction of organic corrosion inhibitors and the surface of metal, isotherms of adsorption are investigated. The obtained data were fitted to the most frequently adsorption isotherms : Temkin, Freundlich and Langmuir, and the correlation coefficients $\left(\mathrm{R}^{2}\right)$ were used to determine the best fits. All three isotherms are suitable for fitting the data, but the best fit is for Langmuir adsorption isotherm. Data fitting for Temkin and Freundlich isotherms are mentioned in Supplementary file.

Takenori et.al showed that adsorption of TTA on Iron substrate obeys Langmuir adsorption isotherm in $3 \% \mathrm{NaCl}$ solution $^{39}$. Also Mahbuboor et. al showed Langmuir is the 
most suitable adsorption isotherm for TTA on copper surface in Synthetic Cooling Water ${ }^{5}$.

The Equation for Langmuir adsorption isotherm is:

$$
\frac{\mathrm{C}}{\theta}=\frac{1}{\mathrm{~K}_{\mathrm{ads}}}+\mathrm{C}
$$

Where $\mathrm{C}, \mathrm{K}_{\text {ads }}$ and $\theta$ are the concentration of the inhibitor, equilibrium constant of adsorptive, and the surface coverage obtained from the EI\% of polarization curves, respectively. The plot of $\mathrm{C} / \theta$ versus $\mathrm{C}(0.01$ to $0.07 \mathrm{M})$ at various temperatures (293-323 K) is represented in Figure 5. TTA adsorption results which obtained from experiments and indicated by linear plots at different temperatures confirm the possibility for approximation of TTA adsorption by Langmuir adsorption isotherm. Langmuir adsorption isotherm showed that polar atoms $(\mathrm{N})$ or groups $\left(\mathrm{CH}_{3}\right)$ in TTA interact by mutual adsorption or desorption ${ }^{43}$.

The adsorption parameters obtained from the plots are presented in Table 3.

Generally, higher inhibition efficiency of a certain inhibitor is confirmed by larger values of $\mathrm{K}_{\text {ads }}$ calculated from the intercepts which is related to its better binding properties on the surface of metal ${ }^{44} . \mathrm{K}_{\text {ads }}$ is a temperaturedependent parameter and decreases with enhancement of temperature which indicates desorption of some adsorbed inhibitors from the metal surface. It is clear that the linear correlation coefficients $\left(\mathrm{R}^{2}\right)$ of the plots are close to unity which reveals that TTA adsorption on the steel surface corresponds to Langmuir adsorption isotherm. However, the slopes, being close to 1 , indicate a non-ideal stimulation of Langmuir adsorption isotherm. The deviation from unity might be a consequence of the interactions between the molecules of adsorbed inhibitor and unsaturated nuclei on the metal surface ${ }^{45}$.

The adsorption heat $\left(\Delta \mathrm{H}_{\text {ads }}\right)$ could be calculated according to the Van't Hoff Equation $3^{46}$ :

$$
\ln \mathrm{K}_{\mathrm{ads}}=\frac{-\Delta \mathrm{H}_{\mathrm{ads}}}{\mathrm{RT}}+\mathrm{D}
$$

Where $\mathrm{D}$ is the constant of integration, $\mathrm{R}$ is the gas constant (8.314 $\left.\mathrm{J} \mathrm{K}^{-1} \mathrm{~mol}^{-1}\right)$, and $\mathrm{T}$ is the absolute temperature $(\mathrm{K})$. Figure 6 represents the linear plot of $\ln \mathrm{K}$ versus 1000/T (the linear correlation coefficient is 0.998). $\Delta \mathrm{H}^{0}$ ads can be calculated from the slope $\left(-\Delta \mathrm{H}^{0}{ }_{\text {ads }} / \mathrm{R}\right)$ as a constant of the adsorptive reactions $\left(\mathrm{kJmol}^{-1}\right)$.

Standard adsorption free energy $\left(\Delta \mathrm{G}_{\text {ads }}^{0}\right)$ could be obtained according to following Equation 4:

$$
\mathrm{K}=\frac{1}{55} \exp \left(\frac{-\Delta \mathrm{G}_{\mathrm{ads}}^{0}}{\mathrm{RT}}\right)
$$

55 is the molar concentration of water ${ }^{47-49}$. The standard adsorption entropy $\left(\Delta \mathrm{S}_{\text {ads }}^{0}\right)$ can be obtained from the following thermodynamic Equation 5:

$\Delta \mathrm{S}_{\mathrm{ads}}^{0}=\frac{\Delta \mathrm{H}_{\mathrm{ads}}^{0}-\Delta \mathrm{G}_{\mathrm{ads}}^{0}}{\mathrm{~T}}$

The calculated thermodynamic parameters of the adsorption isotherms of TTA are listed in Table 4.

Negative values of $\Delta \mathrm{G}^{0}{ }_{\text {ads }}$ and $\Delta \mathrm{H}^{0}{ }_{\text {ads }}$ indicate the exothermic nature of inhibitor adsorption ${ }^{50}$ and also the spontaneous nature of the adsorption of TTA molecules onto the steel surface.

The exothermic behavior of the adsorption reactions may lead to the repulsion of some adsorbed inhibitor molecules

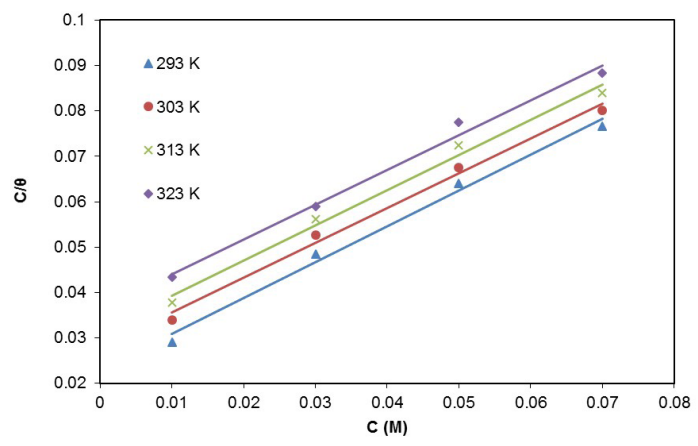

Figure 5. Langmuir adsorption isotherm plots of the steel specimens in $0.5 \mathrm{M} \mathrm{HCl}$ with different concentration of TTA $(0.01$ to $0.07 \mathrm{M})$ at various temperatures $(293,303,313$ and $323 \mathrm{~K})$.

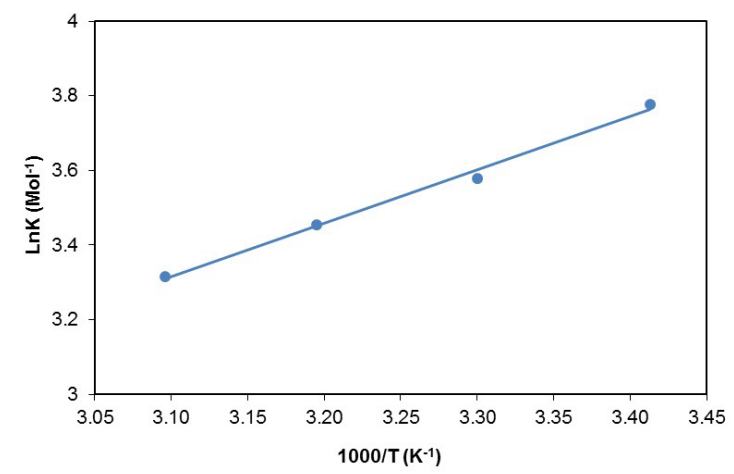

Figure 6. The relation between $\ln _{\text {ads }}\left(\mathrm{M}^{-1}\right)$ and $1000 / \mathrm{T}(\mathrm{K})$ of TTA inhibitor in $0.5 \mathrm{M} \mathrm{HCl}$.

Table 3. Parameters for Langmuir adsorption of mild steel in $0.5 \mathrm{M} \mathrm{HCl}$ solution containing different concentrations of TTA $(0.01$ to 0.07 M) at various temperatures $(293,303,313$ and $323 \mathrm{~K})$.

\begin{tabular}{ccccc}
\hline Isotherm $(\mathrm{K})$ & Intercept & Slope & $\mathrm{R}^{2}$ & $\mathrm{~K}_{\text {ads }}\left(\mathrm{M}^{-1}\right)$ \\
\hline 293 & 0.0229 & 0.7904 & 0.9908 & 43.67 \\
\hline 303 & 0.0279 & 0.7674 & 0.9923 & 35.84 \\
\hline 313 & 0.0316 & 0.7760 & 0.9902 & 31.65 \\
\hline 323 & 0.0363 & 0.7675 & 0.9902 & 27.55 \\
\hline
\end{tabular}


from the metal surface with increase of temperature. Consequently, this can lead to a decrease in inhibition efficiency. This corresponds to the values of IE\% vs. temperature in Figure 3. In the adsorption reactions which the value of $\Delta \mathrm{G}^{0}$ ads is up to $-20 \mathrm{~kJ} \mathrm{~mol}^{-1}$, the adsorption is conducted through the electrostatic interactions between the charged inhibitor molecules and the charged metal surface(physisorption), while in those with the amount of $\Delta \mathrm{G}^{0}{ }_{\text {ads }}$ below $-40 \mathrm{~kJ} \mathrm{~mol}^{-1}$ adsorption involves sharing or transferring electrons between the inhibitor molecules and the metal surface for establishing a chemical bond in between (chemisorption) ${ }^{51,52}$. From Table 4, it is clear that the value of $\Delta \mathrm{G}_{\text {ads }}^{0}$ is about $-20 \mathrm{~kJ} \mathrm{~mol}^{-1}$ which confirms the dominant physical nature of adsorption which is conducted through electrostatic interactions.

$\Delta \mathrm{S}^{0}{ }_{\text {ads }}$ in Table 4 is positive, while adsorption is an exothermic process and expected to be associated with a decrease in entropy. Ateya et al. ${ }^{53}$ described that the adsorption of the organic compound happens with repulsion of water molecules on the surface. They concluded that despite of adsorption process being exothermic for the organic inhibitor which reduces the entropy of the solute, desorption of solvent is endothermic and leads to the increase of entropy. This means that the mentioned coincidence leads to the increase of entropy during desorption of the solvent off the surface. Therefore, the total alteration of entropy during the adsorption process is positive. The positive $\Delta \mathrm{S}^{0}{ }_{\text {ads }}$ means that the adsorption leads to increase the entropy, which is the driving force for the adsorption of inhibitor onto the mild steel surface ${ }^{54}$.

\subsection{Electrochemical impedance spectroscopy measurements}

Electrochemical impedance spectroscopy (EIS) can provide useful information about the resistive and capacitive behavior at the metal/electrolyte solution interface formed by inhibitors additions. Electrochemical impedance spectroscopy (EIS) was used for investigation of TTA corrosion inhibition for mild steel substrate, in $0.5 \mathrm{M} \mathrm{HCl}$ solution after 2 hours of being immersed in $\mathrm{HCl}$ solutions containing 0 to $0.07 \mathrm{M}$ TTA.

Figure 7 and Figure 8 represent the Nyquist and Bode diagrams which have been measured for mild steel in $0.5 \mathrm{M}$ $\mathrm{HCl}$ solution containing various concentrations of TTA.

The radius of semicircles in Nyquist plot can be considered as an indicator for corrosion resistance of under studied systems. As can be seen in Figure 7, the radius of the Nyquist semicircles increased by increasing the inhibitor concentration indicating that the water molecules adsorbed on the mild steel surface were replaced successfully by the inhibitor molecules dissolved in the electrolyte. In addition, the semicircle shape for each measurement in the Nyquist diagram confirms that the corrosion process is activation-controlled and there is

Table 4. Thermodynamic parameters of the adsorption isotherm of TTA on Mild steel surface in $\mathrm{HCl}$ solution.

\begin{tabular}{cccc}
\hline Temperature $(\mathrm{K})$ & $\Delta \mathrm{G}_{\text {ads }}^{0}\left(\mathrm{kJmol}^{-1}\right)$ & $\Delta \mathrm{H}_{\text {ads }}^{0}\left(\mathrm{kJmol}^{-1}\right)$ & -11.88 \\
\hline 293 & -18.98 & -11.88 & 24.25 \\
\hline 303 & -19.13 & -11.88 & 23.95 \\
\hline 313 & -19.44 & -11.88 & 24.17 \\
\hline 323 & -19.69 & $\left.\mathrm{Jmol}^{-1}\right)$ & 24.19 \\
\hline
\end{tabular}

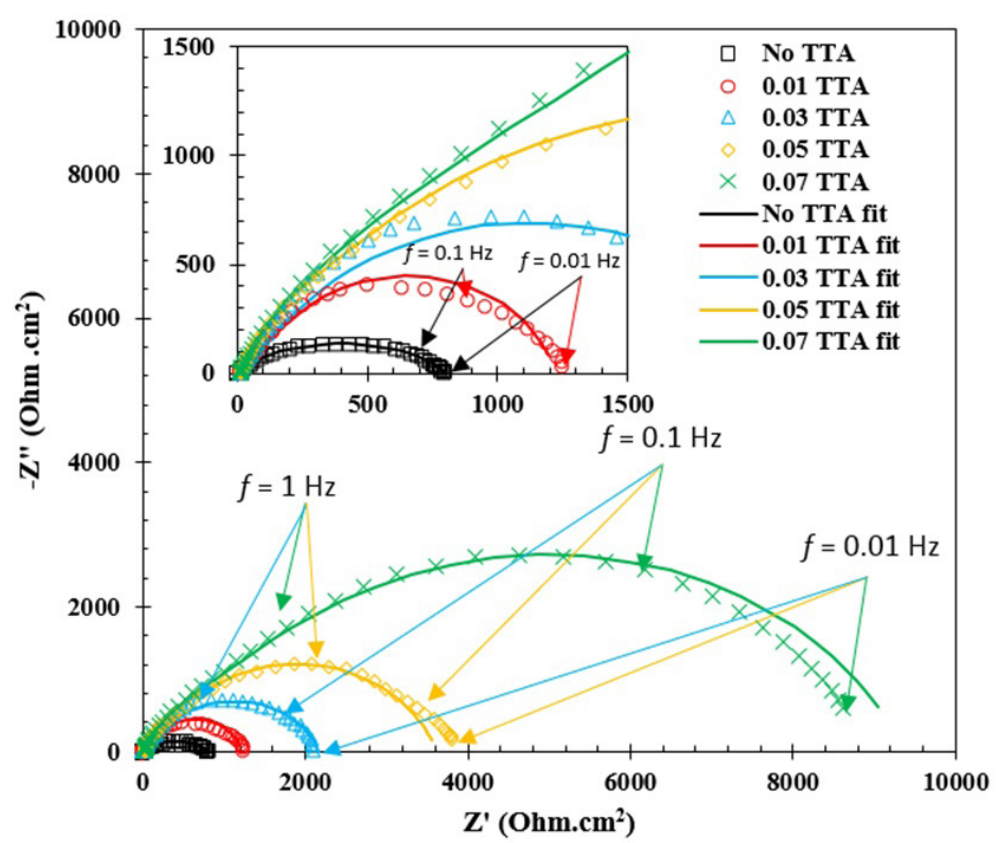

Figure 7. Nyquist diagrams for the corrosion of mild steel in $0.5 \mathrm{M} \mathrm{HCl}$ solution with various concentrations of TTA (0.01 to $0.07 \mathrm{M})$ at $293 \mathrm{~K}$. 
Table 5. Obtained results from the electrochemical modeling of the EIS experimental data on the suitable equivalent circuits.

\begin{tabular}{|c|c|c|c|c|c|c|c|c|c|c|c|}
\hline \multirow{2}{*}{$\begin{array}{l}\text { Concentration } \\
\text { TTA (M) }\end{array}$} & \multirow{2}{*}{$\begin{array}{c}\mathrm{R}_{\mathrm{s}} \\
\left(\Omega \mathrm{cm}^{2}\right)\end{array}$} & \multirow{2}{*}{$\begin{array}{c}\mathrm{R}_{\mathrm{f}} \\
\left(\Omega \mathrm{cm}^{2}\right)\end{array}$} & \multicolumn{2}{|l|}{$\mathrm{CPE}_{\mathrm{f}}$} & \multirow{2}{*}{$\begin{array}{c}\mathrm{C}_{\mathrm{f}} \\
\left(\mu \mathrm{F} \cdot \mathrm{cm}^{2}\right)\end{array}$} & \multirow{2}{*}{$\begin{array}{c}\mathrm{R}_{\mathrm{ct}} \\
\left(\Omega \mathrm{cm}^{2}\right)\end{array}$} & \multicolumn{2}{|l|}{$\mathrm{CPE}_{\mathrm{dl}}$} & \multirow{2}{*}{$\begin{array}{c}\mathrm{C}_{\mathrm{dl}} \\
\left(\mu \mathrm{F} \cdot \mathrm{cm}^{2}\right)\end{array}$} & \multirow{2}{*}{$\begin{array}{c}\mathrm{R}_{\text {total }} \\
\left(\Omega \mathrm{cm}^{2}\right)\end{array}$} & \multirow[b]{2}{*}{ I.E. $(\%)$} \\
\hline & & & 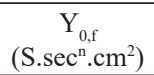 & $\mathrm{n} 1$ & & & $\begin{array}{c}\mathrm{Y}_{0, \mathrm{dl}} \\
\left(\mathrm{S} \cdot \sec ^{\mathrm{n}} \cdot \mathrm{cm}^{2}\right)\end{array}$ & $\mathrm{n} 2$ & & & \\
\hline 0 & 2.14 & - & - & - & - & 740.3 & $2.07 \mathrm{E}-4$ & 0.77 & 118.21 & 740.3 & - \\
\hline 0.01 & 3.58 & 313.3 & $9.22 \mathrm{E}-4$ & 0.53 & 306.53 & 916.4 & $4.22 \mathrm{E}-4$ & 0.79 & 375.25 & 1229.7 & 39.80 \\
\hline 0.03 & 5.84 & 21 & $1.56 \mathrm{E}-4$ & 0.73 & 103.62 & 60.68 & $2.79 \mathrm{E}-4$ & 0.82 & 94.35 & 2181.68 & 66.07 \\
\hline 0.05 & 12.83 & 2466 & $6.77 \mathrm{E}-5$ & 0.87 & 51.81 & 335.6 & $9.66 \mathrm{E}-5$ & 0.85 & 36.72 & 2801.6 & 73.58 \\
\hline 0.07 & 9.27 & 7759 & $5.10 \mathrm{E}-5$ & 0.88 & 38.06 & 744.5 & $6.63 \mathrm{E}-5$ & 0.89 & 31.25 & 8503.5 & 91.29 \\
\hline
\end{tabular}

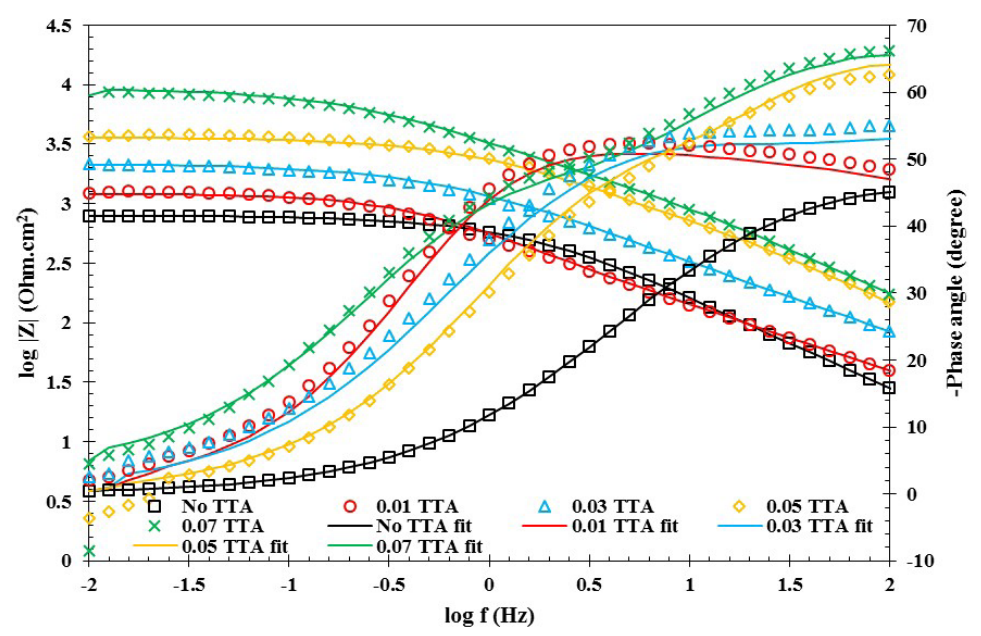

Figure 8. Bode plots for the corrosion of mild steel in $0.5 \mathrm{M} \mathrm{HCl}$ solution with various concentrations of TTA $(0.01$ to $0.07 \mathrm{M})$ at $293 \mathrm{~K}$.

no evidence for diffusion control. Therefore, in the Bode diagrams (Fig. 8), the absolute impedance at low frequencies could indicate the total corrosion resistance of the system. According to Fig 8, the increasing of TTA concentration led to the increase of the absolute impedance at low frequencies, suggesting the formation of a protective layer of the adsorbed inhibitor on the immersed steel surface. Due to the protective layer formation, the charge transfer on the steel surface was inhibited and so the corrosion reactions were significantly affected. More positive phase angle values at the highest frequency in the presence of higher inhibitor concentrations is another prove showing the protective layer formed on the immersed steel surface in the presence of TTA.

Employment of equivalent circuits to model the electrochemical reactions is a well-known technique for interpretation of EIS results ${ }^{55,56}$. The phase angle diagrams depicted in Fig. 8 indicated that except for the blank solution that showed a one-time constant behavior, other samples should be fitted by tow-time constant circuits. The suitable equivalent circuits for both categories of behaviors are shown in Figure 9.

In Figure $9, \mathrm{R}_{\mathrm{s}}$ is solution resistance, $\mathrm{R}_{\mathrm{ct}}$ is charge transfer resistance, and $\mathrm{R}_{\mathrm{f}}$ is the resistance of formed film on the steel surface. Also, in these circuits, $\mathrm{Q}_{\mathrm{dl}}$ and $\mathrm{Q}_{\mathrm{f}}$ are constant phase element (CPE) of double layer and the formed film, respectively. CPE, which is known as the non-ideal capacitance element, is used instead of ideal capacitance to obtain more precious fitting with experimental data. Equation 6 represents the relationship between the values of ideal capacitance $(\mathrm{C})$, resistance $(\mathrm{R})$ and admittance $\left(\mathrm{Y}_{0}\right)$ of $\mathrm{CPE}^{57}$. (a)

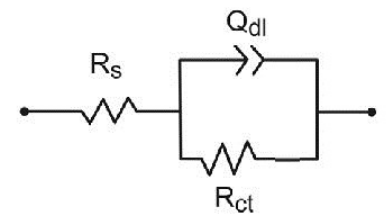

(b)

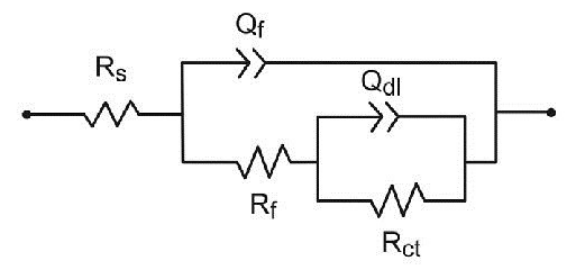

Figure 9. Equivalent circuit model for EIS measurements, a) with TTA and b) without TTA

$\mathrm{C}=\left(\mathrm{Y}_{0}\right)^{1 / \mathrm{n}} \times \mathrm{R}^{(1-\mathrm{n}) / \mathrm{n}}$

In Eq (6), the coefficient " $n$ " represents the depressing feature in Nyquist plots. If $n=1, C P E$ behaves as an ideal capacitor and if $n=0$, it represents a resistor. It is well known that the value of " $n$ " coefficient is attributed to the heterogeneity of the working electrode surface or to continuously distributed time constants for charge-transfer reactions ${ }^{57}$. The obtained parameters from the electrochemical modeling are reported in Table 5 .

In Table $5, \mathrm{R}_{\text {total }}$ is the sum of $\mathrm{R}_{\mathrm{ct}}$ and $\mathrm{R}_{\mathrm{f}}$ values and the inhibition efficiency (I.E.) is calculated by Equation $7^{58-60}$. 


$$
\text { I.E. } \%=100 \times\left(R_{\text {total }}^{i}-R_{\text {total }}{ }^{0}\right) / R_{\text {total }}{ }^{i}
$$

where $\mathrm{R}_{\text {total }}{ }^{\mathrm{i}}$ and $\mathrm{R}_{\text {total }}{ }^{0}$ are the total resistances of the working electrode with and without TTA inhibitor, respectively. As it can be seen from Table $5, \mathrm{R}_{\mathrm{ct}}$ and $\mathrm{R}_{\mathrm{f}}$ values of inhibited substrates simultaneously increase with the enhancement of inhibitors concentration. The highest total resistance belongs to the sample containing $0.07 \mathrm{M} \mathrm{TTA}$. The increasing trend of $n$ values by increasing the inhibitor concentration indicates that the surface homogeneity of the immersed steel is enhanced by formation of a passive layer on $i^{61}$. According to Table 5, the decreasing trend of $\mathrm{C}_{\mathrm{dl}}$ values by increasing the concentration of the inhibitor can be related to the decrease in dielectric constant and/or increase in the thickness of the electrical double layer, due to the film formation on the immersed electrode $^{62}$. In addition, the inhibition efficiency (I.E.\%) increased with the enhancement of inhibitor concentration. A maximum of $91 \%$ inhibition efficiency is achieved with an inhibitor concentration of $0.07 \mathrm{M}$. The calculated inhibition efficiency from the impedance results is consistent with the obtained results in the potentiostatic polarization technique.

\subsection{Scanning electron microscopy (SEM)}

SEM backscattered electrons images of mild steel surfaces after 2 hours of being immersed in $0.5 \mathrm{M} \mathrm{HCl}$ with and without TTA are given in Figure 10. By the comparison of SEM images of mild steel in presence and absence of TTA, the inhibition performance of it can be interpreted. The steel surface in the uninhibited solution (TTA-free solution) is shown in Figure 10a. Some corrosion damages are clearly apparent on the steel surface. Figures $10 \mathrm{~b}$ to $10 \mathrm{e}$ illustrate the surface of the samples in $\mathrm{HCl}$ solutions with 0.01 to 0.07 M TTA, respectively. Bright and smooth areas
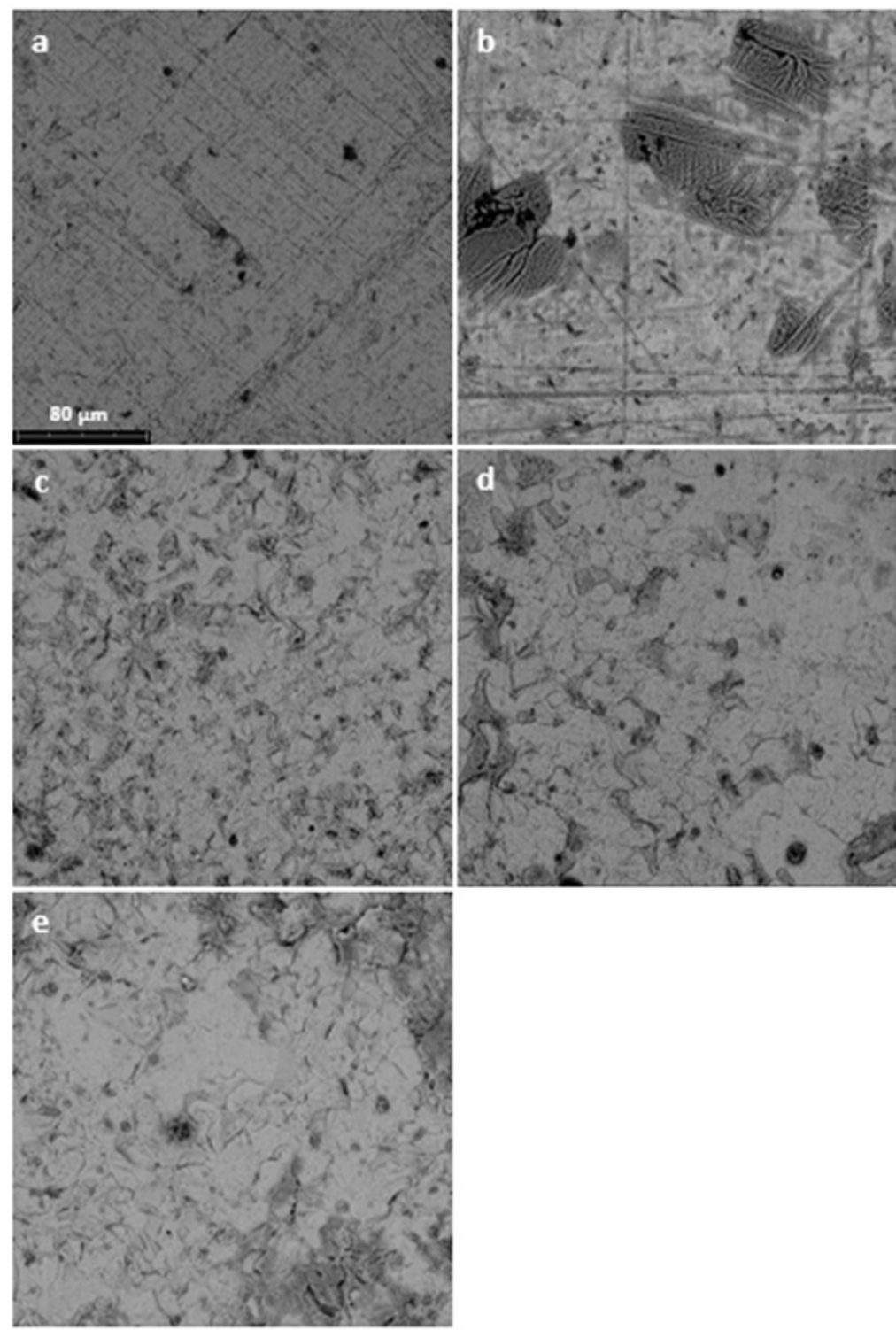

Figure 10. SEM backscattered electron images of mild steel surfaces in the a) absence and in the presence of b) $0.01 \mathrm{M}, \mathrm{c}) 0.03 \mathrm{M}$, d) 0.05 $\mathrm{M}$ and e) $0.07 \mathrm{M}$ TTA exposed to $0.5 \mathrm{M} \mathrm{HCl}$ for $2 \mathrm{~h}$. 
of the images indicate the TTA film adsorbed on the metal surface. The increase of TTA concentration leads to the enhancement of coverage percentage of the surface up to a nearly full coverage (about $91 \%$ ) in $0.07 \mathrm{M}$ TTA. These results suggest that addition of TTA to the corrosive solution results in the successful formation of a uniform barrier layer all over the surface which is responsible for the corrosion inhibition of the mild steel.

\subsection{Energy dispersive X-ray analysis (EDS)}

Determination of elemental composition of steel surface after 2 hours of being in in $0.5 \mathrm{M} \mathrm{HCl}$. was performed by EDS analysis. As it is indicated in Figure 11, the EDS spectra for the specimens show an additional characteristic peak when TTA is present in $0.5 \mathrm{M} \mathrm{HCl}$ solution. This peak is attributed to $\mathrm{N}$ from TTA inhibitor (on $0.392 \mathrm{KeV}$ ) which confirms that TTA molecules are adsorbed on steel surface. Increase of TTA concentration leads to the enhancement of $\mathrm{N}$ peak intensity, while intensity of $\mathrm{Cl}$ peak (on $2.622 \mathrm{KeV}$ ) decreases at the same time. The results demonstrate that adsorption of TTA molecules can lead to a delay in the adsorption of corrosive elements. Also the smooth and uniform TTA layer can reduce the number density of adsorbent sites on the surface.

The appearance of oxygen in the spectra, shows that there are some $\mathrm{Fe}$ or other elements oxides in the surface of the mild steel.

\subsection{Atomic force microscopy (AFM) analysis}

Figure 12 shows the AFM surface topography of mild steel after 8 hours of being immersed in $0.5 \mathrm{M} \mathrm{HCl}$ solutions

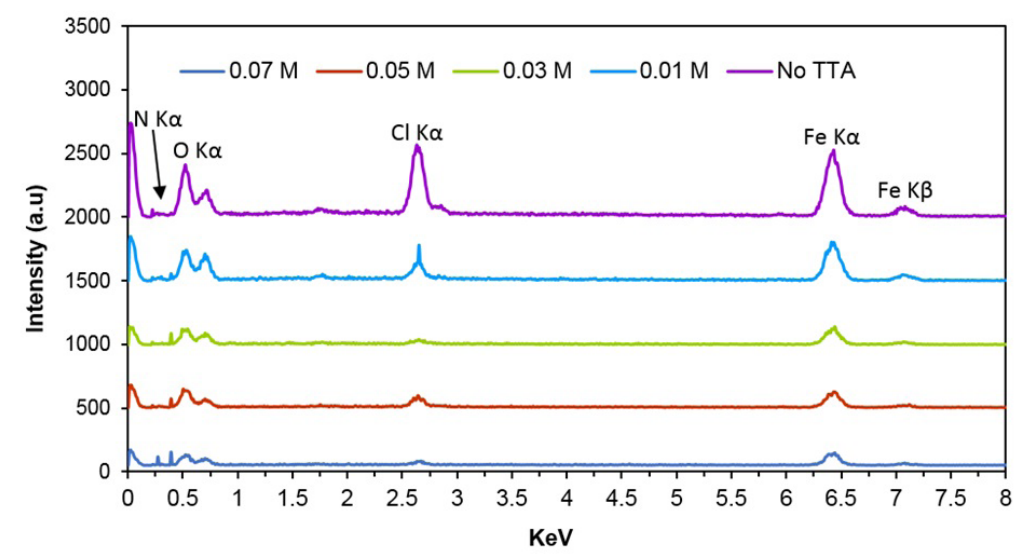

Figure 11. EDS spectra of mild steel surfaces in the a) absence and in the presence of b) $0.01 \mathrm{M}, \mathrm{c}$ ) $0.03 \mathrm{M}$, d) $0.05 \mathrm{M}$ and e) $0.07 \mathrm{M}$ TTA exposed to $0.5 \mathrm{M} \mathrm{HCl}$ for $2 \mathrm{~h}$.
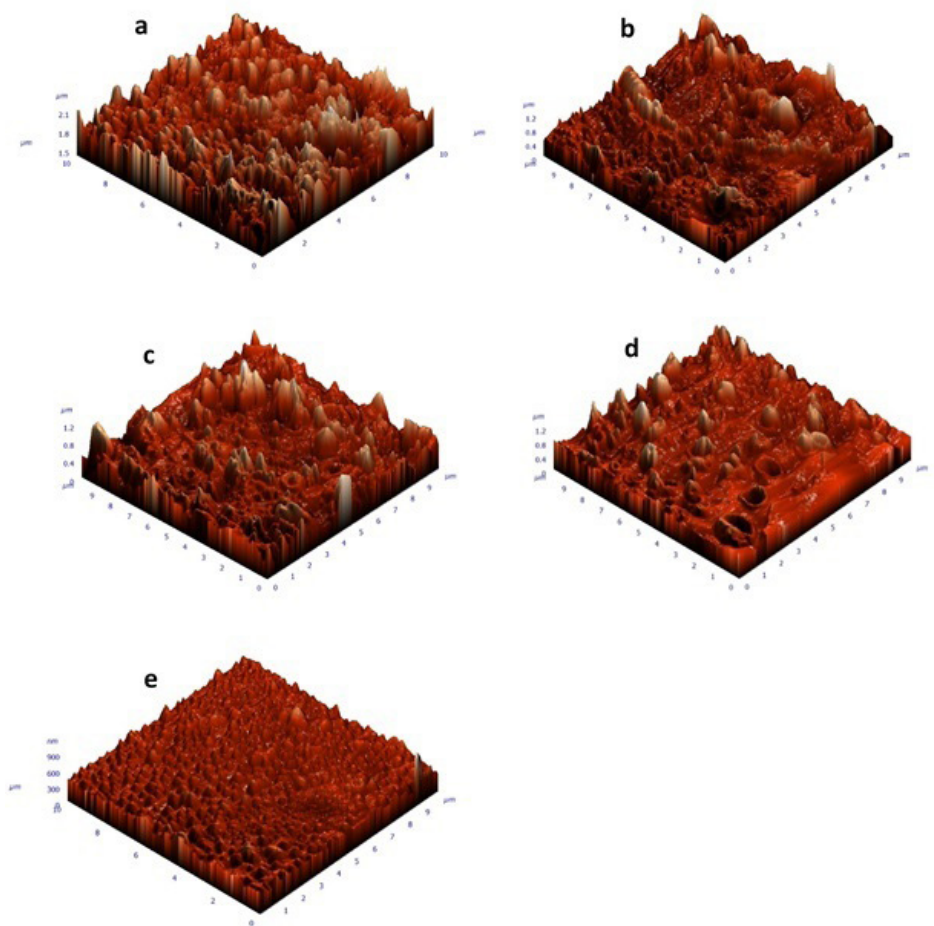

Figure 12. AFM images of mild steel after $8 \mathrm{~h}$ immersion in $0.5 \mathrm{M} \mathrm{HCl}$ containing different concentrations of TTA (a) blank, (b) 0.01 M, (c) $0.03 \mathrm{M}$, (d) $0.05 \mathrm{M}$, (e) $0.07 \mathrm{M}$. 
with and without TTA in different concentrations. The mean surface roughness $\left(\mathrm{R}_{\mathrm{av}}\right)$ is reported to be $208,123,103,95$, and $53 \mathrm{~nm}$ for $0,0.01,0.03,0.05$, and $0.07 \mathrm{M}$ TTA concentrations, respectively. In the absence of TTA, the carbon steel suffers from possible corrosion damages, and its surface is quite rough and uneven, as shown in Figure 12a. When TTA is added into the solutions (from 0.01 to $0.05 \mathrm{M}$ ), the surface of specimens become gradually smoother compared with the uninhibited solution. The reason is the continuous coverage of the surface by gradual formation of a layer of organic film produced by the electrostatic interactions between adsorbed TTA molecules and charged $\mathrm{Fe}$ atoms of the surface, as it is shown in the Figure $12 \mathrm{~b}$ to $12 \mathrm{~d}$. When TTA concentration increases to $0.07 \mathrm{M}$, the surface is smoothed as illustrated in Figure 12e. The reason for significant decrease of surface roughness of the steel surface which is observed in Figure $12 \mathrm{e}$, is the uniform coverage provided by formation a layer of organic film on nearly all over the metal surface in 0.07 M TTA (about $91 \%$ coverage). The organic film can protect the steel surface in two ways : it can form a physical barrier against corrosive elements and also it can reduce the possibility for adsorption of those elements on the probable adsorbent sites through the formation of an even and uniform layer on the surface.

\subsection{X-Ray diffraction analysis}

X-Ray Diffraction (XRD) analysis is a prominent method to determine the fundamental phases or crystallinity of the compounds in corrosion studies. Figure 13 shows the XRD patterns of the surface of the mild steel specimens after 40 minutes of being immersed in $0.5 \% \mathrm{HCl}$ solution with different TTA concentrations ( 0 to $0.07 \mathrm{M}$ ). The XRD patterns and the position of the peaks are fundamentally similar with and without inhibitors. No additional peak is seen which could be related to adsorption of TTA inhibitors. This indicates the probable amorphous nature of organic films. The only difference in the patterns is the reduction of the peak intensities is the only difference between the patterns which is a result of enhancement of TTA concentration. Therefore it can be concluded that TTA inhibitor is prominently physio-adsorbed on the surface of the steel instead of chemisorption of the complexes derived from chemical reactions between TTA and Fe atoms. Due to the physical nature of TTA molecules adsorption, the intensities of the peaks reflected from the surface of the steel specimens are decreased. These results are in agreement with Langmuir isotherm analyses. There are three peaks at $44.637^{\circ}, 64.947^{\circ}$ and $82.332^{\circ}$ can be indexed to (110), (200) and (211) planes respectively which are belong to the Ferrites and Carbides of carbon steel substrate ${ }^{63,64}$.

\subsection{Density functional theory (DFT)}

As it is cleared in Figure 14 there are two probabilities of protonation in the structure of TTA the middle nitrogen and the end one. For the study of the proper position of protonation the structure of each molecule was optimized in neutral and protonated form. The energy difference between the two forms of protonated structures shows the end position is more suitable base on free Gibbs energy of protonation.

The structural and electronic parameters of BTA, TTA-4 and TTA-5 were calculated for the neutral and protonated structure and the results show that there is a strong effect on the chemical properties, specifically in the electron-donating capability to the metal. However, different factors need to be considered for clarifying the orientation of organic molecules on the electrode surface. The atoms and groups of the molecules may interact with the surface depending on the geometry of the inhibitor as well as the nature of their frontier molecular orbitals. Frontier molecular orbital (HOMO and LUMO) theory is useful in predicting the adsorption centers of the inhibitor responsible for the interaction with metal surface. The HOMO and LUMO depictions of the studied benzotriazole family and the cases of protonated forms are shown in Figure 15.

From Figures 15-17, it could be seen that they have same HOMO and LUMO distributions in the neutral and in the protonated forms and are concentrated over the rings. Thus, based on the frontier orbitals, the unoccupied d orbitals of a Fe atom can accept electrons from an inhibitor molecule mainly from central nitrogen as sigma donating centers in the neutral and protonated form. Also, the inhibitor molecule can accept electrons from a Fe atom with its antibonding orbitals with contribution of rings to form a back-donating

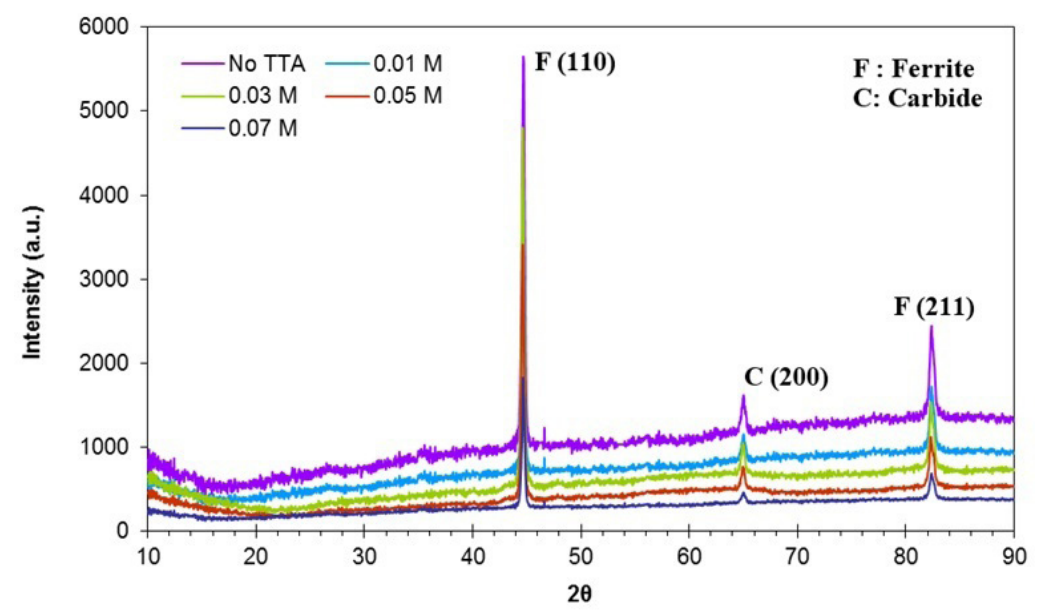

Figure 13. XRD pattern of mild steel surface after $2 \mathrm{~h}$ immersion in $0.5 \mathrm{M} \mathrm{HCl}$ containing different concentrations of TTA (a) blank, (b) $0.01 \mathrm{M}$, (c) $0.03 \mathrm{M}$, (d) $0.05 \mathrm{M}$, (e) $0.07 \mathrm{M}$. 

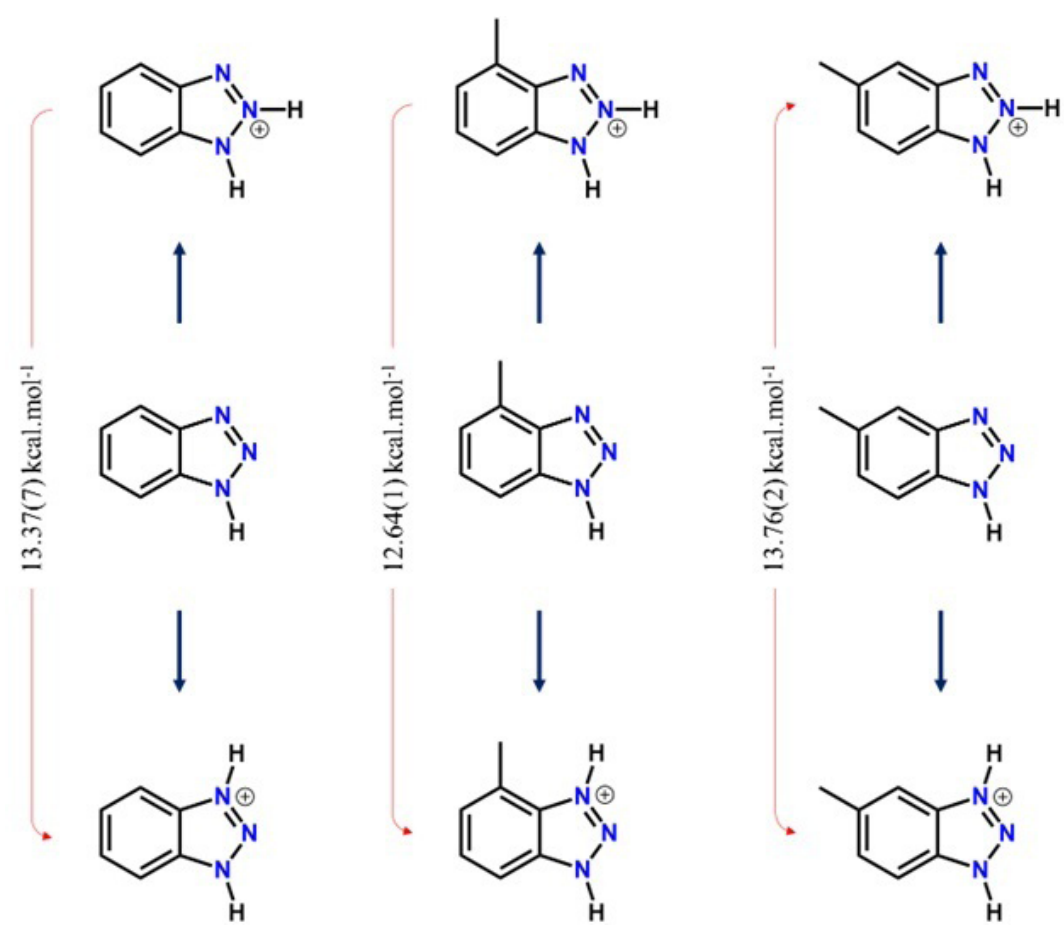

Figure 14. Protonation probabilities in the Structure of BTA and TTA.

Table 6. Quantum physical and chemical parameters of BTA, TTA-4 and TTA-5.

\begin{tabular}{|c|c|c|c|c|c|c|c|c|c|}
\hline \multirow[b]{2}{*}{ Parameter } & \multicolumn{3}{|c|}{ BTA } & \multicolumn{3}{|c|}{ TTA-4 } & \multicolumn{3}{|c|}{ TTA-5 } \\
\hline & Neutral & $\begin{array}{l}\text { Protonated } \\
\text { Middle }\end{array}$ & $\begin{array}{l}\text { Protonated } \\
\text { End }\end{array}$ & Neutral & $\begin{array}{l}\text { Protonated } \\
\text { Middle }\end{array}$ & $\begin{array}{l}\text { Protonated } \\
\text { End }\end{array}$ & Neutral & $\begin{array}{l}\text { Protonated } \\
\text { Middle }\end{array}$ & $\begin{array}{l}\text { Protonated } \\
\text { End }\end{array}$ \\
\hline LUMO & $-0.037(7)$ & $-0.251(8)$ & $-0.245(4)$ & $-0.034(1)$ & $-0.245(2)$ & $-0.238(7)$ & $-0.036(3)$ & $-0.245(9)$ & $-0.239(0)$ \\
\hline HOMO & $-0.252(4)$ & $-0.430(1)$ & $-0.438(9)$ & $-0.243(2)$ & $-0.412(8)$ & $-0.422(7)$ & $-0.243(7)$ & $-0.414(7)$ & $-0.424(6)$ \\
\hline HOMO-1 & $-0.264(7)$ & $-0.456(4)$ & $-0.453(2)$ & $-0.260(6)$ & $-0.449(6)$ & $-0.446(3)$ & $-0.259(8)$ & $-0.443(8)$ & $-0.439(8)$ \\
\hline HOMO-2 & $-0.280(4)$ & $-0.519(9)$ & $-0.548(9)$ & $-0.277(9)$ & $-0.510(0)$ & $-0.533(4)$ & $-0.277(7)$ & $-0.509(2)$ & $-0.522(3)$ \\
\hline HOMO-3 & $-0.337(5)$ & $-0.550(6)$ & $-0.559(3)$ & $-0.328(6)$ & $-0.523(8)$ & $-0.538(7)$ & $-0.333(4)$ & $-0.523(8)$ & $-0.536(8)$ \\
\hline $\begin{array}{l}\text { LUMO - } \\
\text { HOMO }\end{array}$ & 0.215 & 0.179 & 0.193 & 0.209 & 0.167 & 0.184 & 0.207 & 0.169 & 0.185 \\
\hline $\begin{array}{c}\text { HOMO - } \\
\text { (HOMO-1) }\end{array}$ & 0.012 & 0.026 & 0.015 & 0.017 & 0.037 & 0.024 & 0.016 & 0.029 & 0.015 \\
\hline $\begin{array}{c}\text { (HOMO-1) - } \\
\text { (HOMO-2) }\end{array}$ & 0.016 & 0.063 & 0.095 & 0.017 & 0.061 & 0.084 & 0.018 & 0.066 & 0.083 \\
\hline
\end{tabular}

bond mainly in the protonated form. These donation and back-donation processes strengthen the adsorption of inhibitors onto the surface.

Based on Koopman's theorem ${ }^{65} \mathrm{E}_{\text {номо }}$ is often associated with the electron donating ability of a molecule; high values of $\mathrm{E}_{\text {номо }}$ are likely to indicate the tendency of the molecule to donate electrons to appropriate acceptor molecules with lower energy MO. $\mathrm{E}_{\text {LuMO }}$, on the other hand, indicates the ability of the molecule to accept electrons.

$\mathrm{I}=-\mathrm{E}_{\mathrm{HOMO}}$

$$
\mathrm{A}=-\mathrm{E}_{\mathrm{LUMO}}
$$

The binding ability of the inhibitor to the surface of metal increases with increasing HOMO and decreasing LUMO energy.
Consequently, the lower the value of $\mathrm{E}_{\mathrm{LUMO}}$, the most probable it is that the molecule would accept electrons. Moreover, the energy gap between the HOMO and LUMO orbitals of the molecule is an important parameter that determines the reactivity of the inhibitor molecule toward the adsorption on the metallic surface. As $\Delta \mathrm{E}$ decreases (most especially for the cationic species), the reactivity of the molecule increases leading to an increase in the inhibition efficiency of the molecule ${ }^{66}$. For effective overlapping, the energy difference between the orbitals generally must be low, and the overall energy difference between the orbitals HOMO and HOMO-1) indicating their participation in the metal-ligand interaction. In addition, the energy difference between the HOMO-2 and HOMO-1 for the studied structures is so low confirming the involvement of HOMO-1 and HOMO-2 in the ligand-metal interaction (Table 6). A similar observation is also noted for the protonated structures, suggesting that the parameters of 
Table 7. Calculated theoretical quantum parameters of BTA, TTA-4 and TTA-5.

\begin{tabular}{|c|c|c|c|c|c|c|c|c|c|}
\hline & \multicolumn{3}{|c|}{ BTA } & \multicolumn{3}{|c|}{ TTA-4 } & \multicolumn{3}{|c|}{ TTA-5 } \\
\hline & BTA & M-HBTA $^{+}$ & E-HBTA $^{+}$ & TTA & M-HTTA $^{+}$ & E-HTTA $^{+}$ & TTA & M-HTTA $^{+}$ & E-HTTA $^{+}$ \\
\hline I & $0.252(4)$ & $0.430(1)$ & $0.438(9)$ & $0.243(2)$ & $0.412(8)$ & $0.422(7)$ & $0.243(7)$ & $0.414(7)$ & $0.424(6)$ \\
\hline $\mathrm{A}$ & $0.037(7)$ & $0.251(8)$ & $0.245(4)$ & $0.034(1)$ & $0.245(2)$ & $0.238(7)$ & $0.036(3)$ & $0.245(9)$ & $0.239(0)$ \\
\hline$\eta$ & $0.107(3)$ & $0.089(1)$ & $0.096(7)$ & $0.1045(4)$ & $0.083(8)$ & $0.092(0)$ & $0.103(7)$ & $0.084(4)$ & $0.092(8)$ \\
\hline$\sigma$ & $4.657(4)$ & $5.609(7)$ & $5.169(0)$ & $4.782(6)$ & $5.967(6)$ & $5.434(7)$ & $4.821(1)$ & $5.924(1)$ & $5.386(1)$ \\
\hline$\chi$ & $0.145(1)$ & $0.341(0)$ & $0.342(1)$ & $0.138(7)$ & $0.329(0)$ & $0.330(7)$ & $0.139(9)$ & $0.330(2)$ & $0.331(8)$ \\
\hline$\mu$ & $0.145(1)$ & $0.341(0)$ & $0.342(1)$ & $0.138(7)$ & $0.329(0)$ & $0.330(7)$ & $0.139(9)$ & $0.330(2)$ & $0.331(8)$ \\
\hline$\omega$ & $0.098(1)$ & $0.652(2)$ & $0.605(2)$ & $0.091(9)$ & $0.645(9)$ & $0.594(2)$ & $0.094(4)$ & $0.646(1)$ & $0.593(1)$ \\
\hline
\end{tabular}
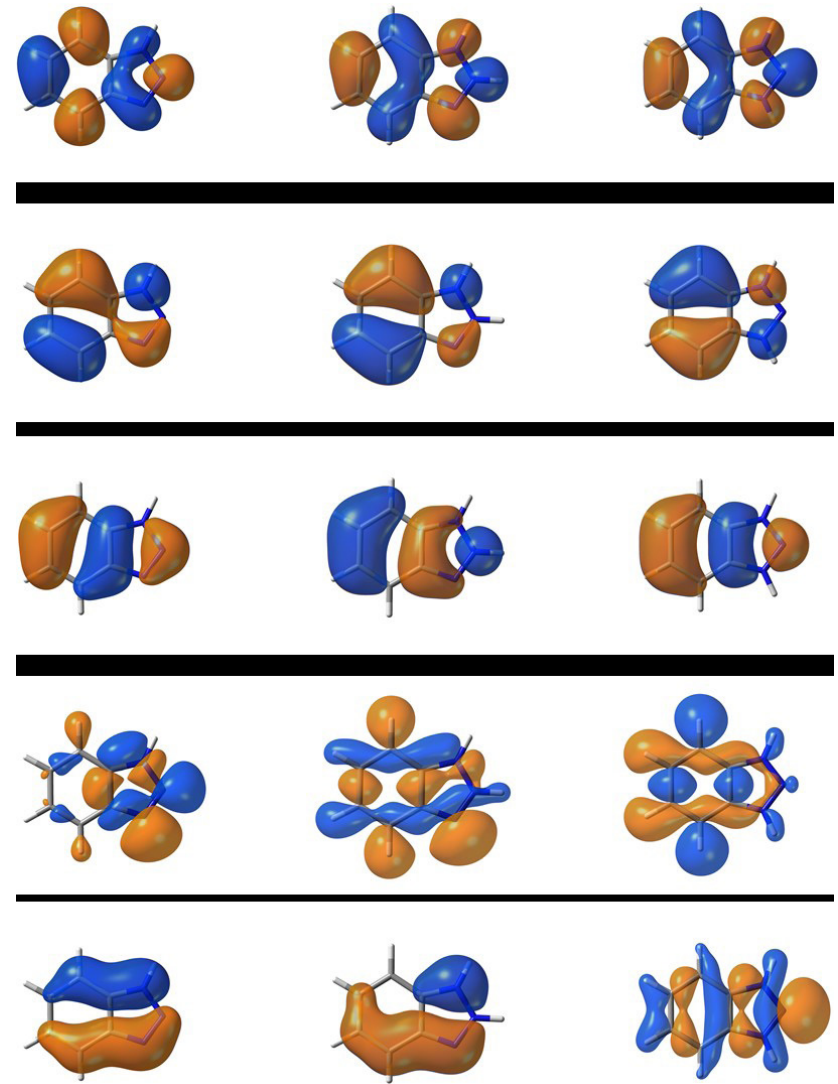

Figure 15. Molecular Orbitals of (a) BTA, (b) $\mathrm{HBTA}^{+}$and (c) $\mathrm{HBTA}^{+}$

orbitals such as HOMO, HOMO-1, and HOMO-2 are important for chemical reactivity over the iron surface ${ }^{67}$.

It is evident from Table 6 that TTA-4\&5 have the highest $\mathrm{E}_{\text {номо }}$ in the neutral form and a lower $\mathrm{E}_{\text {номо }}$ in the protonated form. This means that the electron donating ability of theme are weaker in the protonated form. It is clear from Table 6 that the protonated form of BTA exhibits the lowest $\mathrm{E}_{\text {LUMO }}$, making the protonated form the most likely form for the interaction of mild steel with $\mathrm{BTAH}^{+}$molecule. The calculations further show that TTA- 5 in the protonate form has the smallest $\Delta \mathrm{E}$ value $(0.185 \mathrm{eV})$ indicating that $\mathrm{TTAH}^{+}-5$ is the most reactive inhibitor that can easily adsorb on the metal surface causing higher protection. This agrees with the experimental results that TTA- 5 could have better inhibitive performance on mild steel surface in the protonated form i.e. through electrostatic interaction between the cation form of TTA- 5 and the vacant d-orbital of steel. Moreover, the adsorption of TTA- 5 on the steel surface using the neutral form also plays a part in the overall inhibiting process.

Absolute hardness, $\eta$, and softness, $\sigma$, are important properties to measure the molecular stability and reactivity. A hard molecule has a large energy gap, and a soft molecule has a small energy gap. Soft molecules are more reactive than hard ones because they could easily offer electrons to an acceptor. For the simplest transfer of electrons, adsorption could occur at the part of the molecule where $\sigma$ has the highest value and $\eta$ the lowest value. The result from Table 7 shows that TTA- 4 \& 5 in the protonated form has the lowest energy gap, lowest hardness, and the highest softness; this agrees with the experimental results that TTA could have a better inhibitive performance on the mild steel surface in the protonated form i.e. through electrostatic interaction between the cation form of TTA and the vacant d-orbital of steel. Density functional theory (DFT) has been found to be successful in providing intuitions into the 


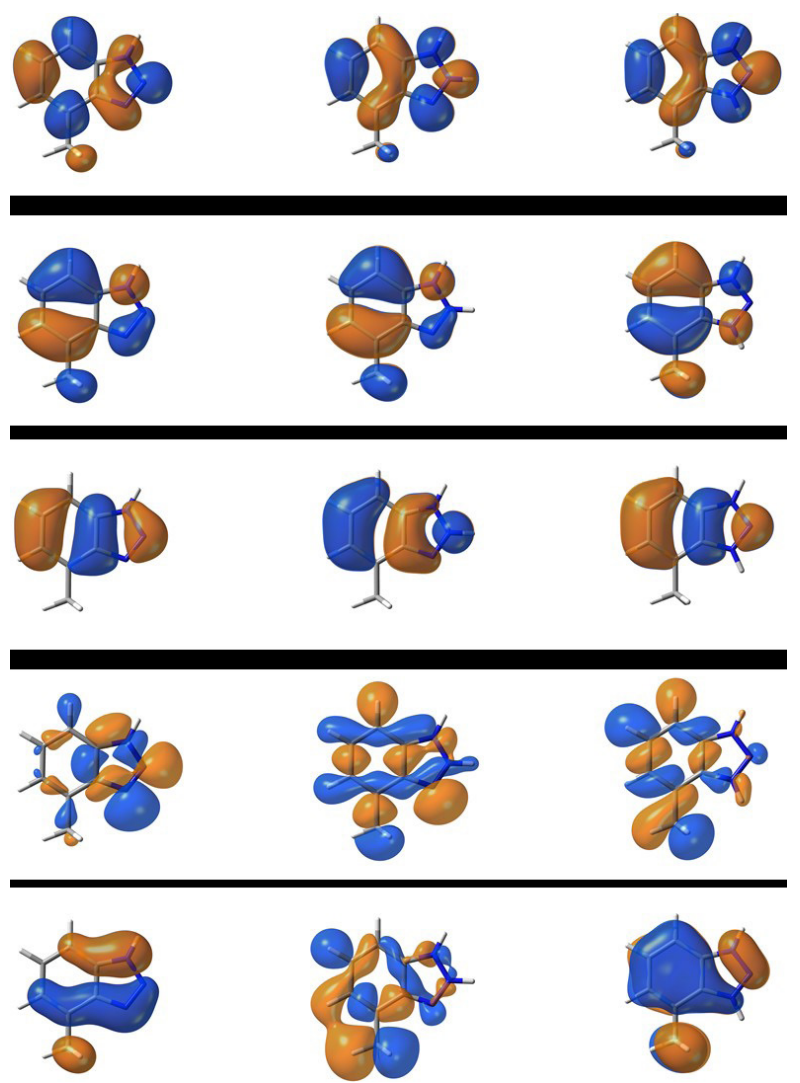

Figure 16. Molecular Orbitals of (a) TTA-4, (b) $\mathrm{HTTA}^{+}$and (c) $\mathrm{HTTA}^{+}$
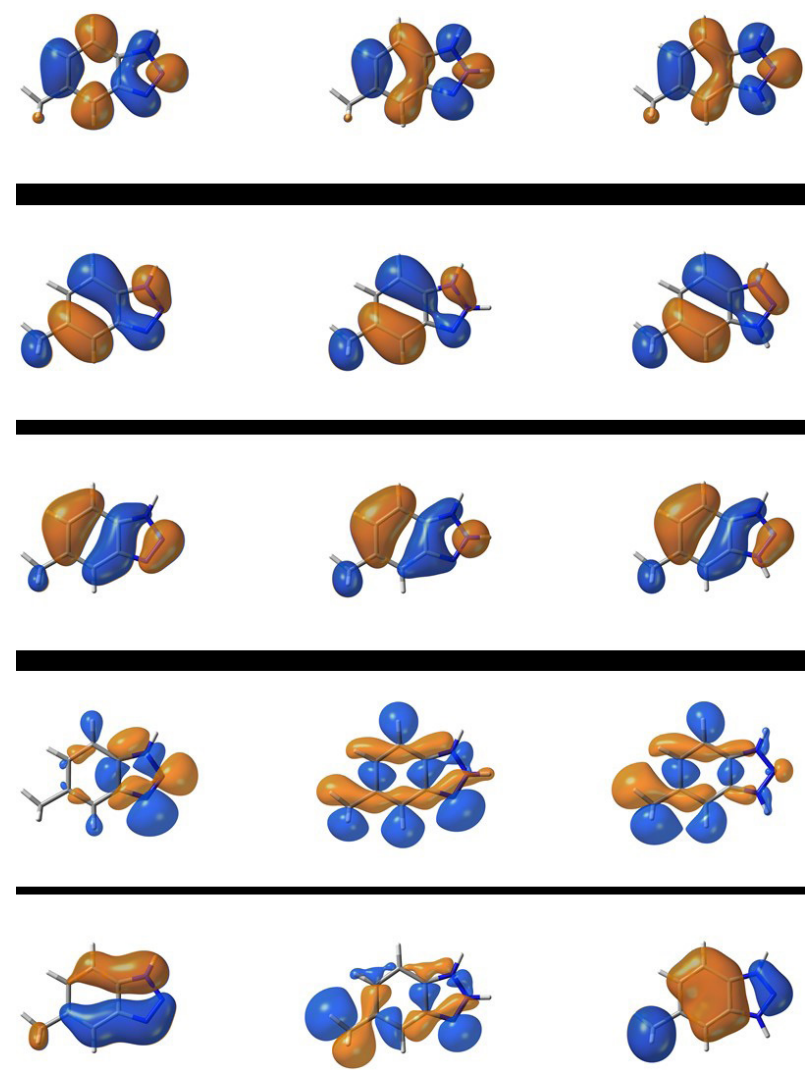

Figure 17. Molecular Orbitals of (a) TTA-5, (b) $\mathrm{HTTA}^{+}$and (c) $\mathrm{HTTA}^{+}$ 
chemical reactivity and selectivity, in terms of global parameters such as electronegativity $(\chi)$, hardness $(\eta)$ and softness $(\sigma)$. Table 7 shows the calculated quantum theoretical parameters which provide information about the reactive behavior of BTA, TTA-4 and TTA-5 and their protonated structures.

\section{Conclusion}

TTA shows a high efficiency for corrosion inhibitioan which is about $91 \%$ for mild steel with a concentration of $0.07 \mathrm{M}$ in $0.5 \mathrm{M} \mathrm{HCl}$ at room temperature. It is also found that inhibition properties of TTA are maintained up to a certain temperature which indicates that it can tolerate a certain level of temperature enhancement. Electrochemical studies revealed that TTA is a hybrid (anodic and cathodic) corrosion inhibitor which obeys the Langmuir adsorption isotherm. The increase of TTA concentration leads to the shift of OCP and polarization curves to the more positive potentials, and also enhancement of the corrosion resistance which is caused by the reduction of the corrosion current. Surface analysis indicates the formation of a uniform and stable organic film on metal surface as a result of physical adsorption of TTA molecules which protects the surface against the corrosion by $\mathrm{HCl}$ solution. XRD and AFM results demonstrate that increase of TTA concentration results in the enhancement of coverage and thickness of the amorphous protective film, while the roughness of the film formed on the substrate surface significantly decreases which may result in the decrease of adsorptivity for corrosive elements $\left(\mathrm{Cl}^{-}\right)$, as can be confirmed by EDS results. DFT confirmed that TTA in protonated form, has excellent corrosion inhibition performance for mild steel in acidic media.

\section{Acknowledgments}

The authors are grateful to Iran National Science Foundation (INSF) for the fund of project (number 97012056) and also Research Deputy of Sharif University for partial financial support.

\section{References}

1. Sheir L, Jarman R, Burstein G. Corrosion. Vol. 2. USA: Elsevier; 2010.

2. Fontana MG. Corrosion engineering. New York: McGraw-Hill Education; 1987.

3. Parthipan P, Narenkumar J, Elumalai P, Preethi PS, Nanthini AUR, Agrawal A, et al. Neem extract as a green inhibitor for microbiologically influenced corrosion of carbon steel API 5LX in a hypersaline environments. J Mol Liq. 2017;240:121-7.

4. Narenkumar J, AlSalhi MS, Arul Prakash A, Abilaji S, Devanesan S, Rajasekar A, et al. Impact and role of bacterial communities on biocorrosion of metals used in the processing industry. ACS Omega. 2019

5. Choudhury MR, Vidic RD, Dzombak DA. Inhibition of copper corrosion by tolyltriazole in cooling systems using treated municipal wastewater as makeup water. Arab J Sci Eng. 2014;39(11):7741-9.

6. Hsieh M-K, Dzombak DA, Vidic RD. Effect of tolyltriazole on the corrosion protection of copper against ammonia and disinfectants in cooling systems. Ind Eng Chem Res. 2010;49(16):7313-22.

7. Fateh A, Aliofkhazraei M, Rezvanian AR. Review of corrosive environments for copper and its corrosion inhibitors. Arab J Chem. 2017

8. Gomma GK. Effect of azole compounds on corrosion of copper in acid medium. Mater Chem Phys. 1998;56(1):27-34.
9. Xhanari K, Finšgar M. Organic corrosion inhibitors for aluminum and its alloys in chloride and alkaline solutions: A review. Arab J Chem. 2016

10. Kovačević N, Kokalj A. DFT Study of Interaction of Azoles with $\mathrm{Cu}(111)$ and $\mathrm{Al}(111)$ Surfaces: Role of Azole Nitrogen Atoms and Dipole-Dipole Interactions. J Phys Chem C. 2011;115(49):24189-97.

11. Önal AN, Aksüt AA. Corrosion inhibition of aluminium alloys by tolyltriazole in chloride solutions. Anti-Corros Methods Mater. 2000;47(6):339-49.

12. Finšgar M, Jackson J. Application of corrosion inhibitors for steels in acidic media for the oil and gas industry: A review. Corros Sci. 2014;86:17-41.

13. Abdallah M, Atwa ST, Abd-Allah NM, Fouda AS. Azole derivatives as inhibitors for the corrosion of irradiated and non-irradiated carbon steel in HNO3 solution. Anti-Corros Methods Mater. 2011;58(1):31-8.

14. Şahin M, Bilgic S, Yllmaz H. The inhibition effects of some cyclic nitrogen compounds on the corrosion of the steel in $\mathrm{NaCl}$ mediums. Appl Surf Sci. 2002;195(1-4):1-7.

15. Hsieh M-K, Li H, Chien S-H, Monnell JD, Chowdhury I, Dzombak DA, et al. Corrosion control when using secondary treated municipal wastewater as alternative makeup water for cooling tower systems. Water Environ Res. 2010;82(12):731322.

16. Landoulsi J, Cooksey K, Dupres V. Review-interactions between diatoms and stainless steel: focus on biofouling and biocorrosion. Biofouling. 2011;27(10):1105-24.

17. Li XL, Narenkumar J, Rajasekar A, Ting Y-P. Biocorrosion of mild steel and copper used in cooling tower water and its control. 3 Biotech. 2018;8(3):178.

18. Aruliah R, Ting Y-P. Characterization of corrosive bacterial consortia isolated from water in a cooling tower. ISRN Corrosion. 2014:2014:803219.

19. Narenkumar J, Elumalai P, Subashchandrabose S, Megharaj M, Balagurunathan R, Murugan K, et al. Role of 2-mercaptopyridine on control of microbial influenced corrosion of copper CW024A metal in cooling water system. Chemosphere. 2019;222:611-8.

20. Zhang Y, Ma Y, Duan J, Li X, Wang J, Hou B. Analysis of marine microbial communities colonizing various metallic materials and rust layers. Biofouling. 2019;35(4):429-42.

21. Narenkumar J, Sathishkumar K, Sarankumar RK, Murugan $\mathrm{K}$, Rajasekar A. An anticorrosive study on potential bioactive compound produced by Pseudomonas aeruginosa TBH2 against the biocorrosive bacterial biofilm on copper metal. J Mol Liq. 2017;243:706-13.

22. Narenkumar J, Ramesh N, Rajasekar A. Control of corrosive bacterial community by bronopol in industrial water system. 3 Biotech. 2018;8(1):55.

23. Törnkvist C, Thierry D, Bergman J, Liedberg B, Leygraf C. Methyl substitution in benzotriazole and its influence on surface structure and corrosion inhibition. J Electrochem Soc. 1989;136(1):58-64.

24. Hollander O, May RC. The chemistry of azole copper corrosion inhibitors in cooling waters. Corrosion. 1985;41(1):39-45.

25. Notoya T, Poling GW. Benzotriazole and tolyltriazole as corrosion inhibitors for copper and brasses. Boshoku Gijutsu. 1981;30(7):381-9.

26. Cotton J, Scholes I. Benzotriazole and related compounds as corrosion inhibitors for copper. Br Corros J. 1967;2(1):1-5.

27. Xu Z, Lau S, Bohn PW. The role of benzotriazole in corrosion inhibition: formation of an oriented monolayer on $\mathrm{Cu} 2 \mathrm{O}$. Surf Sci. 1993;296(1):57-66.

28. Fang B-S, Olson CG, Lynch DW. A photoemission study of benzotriazole on clean copper and cuprous oxide. Surf Sci. 1986;176(3):476-90.

29. Yadav M, Behera D, Kumar S, Sinha RR. Experimental and quantum chemical studies on the corrosion inhibition performance 
of benzimidazole derivatives for mild steel in $\mathrm{HCl}$. Ind Eng Chem Res. 2013;52(19):6318-28.

30. Subramanyam N, Mayanna S. Azoles as corrosion inhibitors for mild steel in alkaline mine water. Corros Sci. 1985;25(3):163-9.

31. Feng Y, Cheng YF. Inhibitive performance of benzotriazole for steel corrosion studied by electrochemical and AFM characterization. J Mater Eng Perform. 2015;24(12):4997-5001.

32. Oguike R, Kolo A, Shibdawa A, Gyenna H. Density functional theory of mild steel corrosion in acidic media using dyes as inhibitor: adsorption onto $\mathrm{Fe}$ (110) from gas phase. International Scholarly Research Notices. 2013;175910.

33. Camacho-Mendoza RL, Gutiérrez-Moreno E, GuzmánPercástegui E, Aquino-Torres E, Cruz-Borbolla J, RodríguezÁvila JA, et al. Density functional theory and electrochemical studies: structure-efficiency relationship on corrosion inhibition. J Chem Inf Model. 2015;55(11):2391-402.

34. Shojaie F, Mirzai-Baghini N. Molecular dynamics and density functional theory study on the corrosion inhibition of austenitic stainless steel in hydrochloric acid by two pyrimidine compounds. International Journal of Industrial Chemistry. 2015;6(4):297310.

35. Nezafati M. Density Functional Theory (DFT) Study on the Hydrolysis Behavior of Degradable $\mathrm{Mg} / \mathrm{Mg}$ Alloys for Biomedical Applications [thesis]. Milwaukee: University of Wisconsin-Milwaukee; 2013.

36. Ke H, Taylor CD. Density functional theory: an essential partner in the integrated computational materials engineering approach to corrosion. Corrosion. 2019;75(7):708-26.

37. Verma DK. Density functional theory (DFT) as a powerful tool for designing corrosion inhibitors in aqueous phase. In: Ali A. Advanced engineering testing. London: IntechOpen; 2018. p. 87.

38. Obot I, Macdonald D, Gasem Z. Density functional theory (DFT) as a powerful tool for designing new organic corrosion inhibitors. Part 1: an overview. Corros Sci. 2015;99:1-30.

39. Notoya T, Ishikawa T. Benzotriazole and its derivatives as corrosion inhibitors for iron in sodium chloride solutions. Bulletin of the Faculty of Engineering. 1982;110:119-24.

40. Verma C, Obot I, Bahadur I, Sherif E-SM, Ebenso EE. Choline based ionic liquids as sustainable corrosion inhibitors on mild steel surface in acidic medium: Gravimetric, electrochemical, surface morphology, DFT and Monte Carlo simulation studies. Appl Surf Sci. 2018;457:134-49.

41. Liu F, Du M, Zhang J, Qiu M. Electrochemical behavior of Q235 steel in saltwater saturated with carbon dioxide based on new imidazoline derivative inhibitor. Corros Sci. 2009;51(1):102-9.

42. Umoren S, Eduok U, Oguzie E. Corrosion inhibition of mild steel in $1 \mathrm{MH} 2 \mathrm{so} 4$ by polyvinyl pyrrolidone and synergistic iodide additives. Port Electrochem Acta. 2008;26(6):533-46.

43. Manimegalai S, Manjula P. Thermodynamic and adsorption studies for corrosion inhibition of mild steel in aqueous media by Sargasam swartzii (brown algae). Journal of Material and Environmental Science. 2015;6(6):1629-37.

44. Singh AK, Quraishi M. The effect of some bis-thiadiazole derivatives on the corrosion of mild steel in hydrochloric acid. Corros Sci. 2010;52(4):1373-85.

45. Negm N, Elkholy Y, Zahran M, Tawfik S. Corrosion inhibition efficiency and surface activity of benzothiazol-3-ium cationic Schiff base derivatives in hydrochloric acid. Corros Sci. 2010;52(10):3523-36.

46. Li X, Deng S, Mu G, Fu H, Yang F. Inhibition effect of nonionic surfactant on the corrosion of cold rolled steel in hydrochloric acid. Corros Sci. 2008;50(2):420-30.

47. Moretti G, Guidi F, Grion G. Tryptamine as a green iron corrosion inhibitor in $0.5 \mathrm{M}$ deaerated sulphuric acid. Corros Sci. 2004;46(2):387-403.

48. Do DD. Adsorption analysis: equilibria and kinetics. London: Imperial College Press; 1998.
49. Gomma GK, Wahdan MH. Effect of temperature on the acidic dissolution of copper in the presence of amino acids. Mater Chem Phys. 1994;39(2):142-8.

50. Gomma GK, Wahdan MH. Schiff bases as corrosion inhibitors for aluminium in hydrochloric acid solution. Mater Chem Phys. 1995;39(3):209-13.

51. Donahue FM, Nobe K. Theory of organic corrosion inhibitors adsorption and linear free energy relationships. J Electrochem Soc. 1965;112(9):886-91.

52. Khamis E, Bellucci F, Latanision R, El-Ashry E. Acid corrosion inhibition of nickel by 2-(triphenosphoranylidene) succinic anhydride. Corrosion. 1991;47(9):677-86.

53. Ateya B, El-Anadouli B, El-Nizamy F. The adsorption of thiourea on mild steel. Corros Sci. 1984;24(6):509-15.

54. Emranuzzaman KT, Vishwanatham S, Udayabhanu G. Synergistic effects of formaldehyde and alcoholic extract of plant leaves for protection of $\mathrm{N} 80$ steel in 15\% HCl. Corros Eng Sci Technol. 2004;39(4):327-32.

55. Shahmoradi A, Talebibahmanbigloo N, Javidparvar A, Bahlakeh G, Ramezanzadeh B. Studying the adsorption/inhibition impact of the cellulose and lignin compounds extracted from agricultural waste on the mild steel corrosion in $\mathrm{HCl}$ solution. J Mol Liq. 2020;304(1-2):112751.

56. Javidparvar AA, Naderi R, Ramezanzadeh B. Manipulating graphene oxide nanocontainer with benzimidazole and cerium ions: application in epoxy-based nanocomposite for active corrosion protection. Corros Sci. 2020;165:108379.

57. Pourhashem S, Vaezi MR, Rashidi A. Investigating the effect of SiO2-graphene oxide hybrid as inorganic nanofiller on corrosion protection properties of epoxy coatings. Surf Coat Tech. 2017;311:282-94.

58. Singh A, Caihong Y, Yaocheng Y, Soni N, Wu Y, Lin Y. Analyses of new electrochemical techniques to study the behavior of some corrosion mitigating polymers on N80 tubing steel. ACS Omega. 2019;4(2):3420-31.

59. Wang H. Electrochemical investigation of" green" filmforming corrosion inhibitors [thesis]. Sweden: Royal Institute of Technology Stockholm, 2011.

60. Baux J, Caussé N, Esvan J, Delaunay S, Tireau J, Roy M, et al. Impedance analysis of film-forming amines for the corrosion protection of a carbon steel. Electrochim Acta. 2018;283:699707.

61. Javidparvar AA, Naderi R, Ramezanzadeh B. L-cysteine reduced/functionalized graphene oxide application as a smart/ control release nanocarrier of sustainable cerium ions for epoxy coating anti-corrosion properties improvement. J Hazard Mater. 2020;389:122135.

62. Geethanjali R, Subhashini S. Synthesis of magnetite-containing polyaniline-polyacrylamide nanocomposite, characterization and corrosion inhibition behavior on mild steel in acid media. Chem Sci Trans. 2013;2(4):1148-59.

63. Sinha PK, Kumar MK, Kain V. Effect of microstructure of carbon steel on magnetite formation in simulated Hot Conditioning environment of nuclear reactors. J Nucl Mater. 2015;464:20-7.

64. Crane R, Scott T. The effect of vacuum annealing of magnetite and zero-valent Iron nanoparticles on the removal of aqueous uranium. Journal of Nanotechnology. 2013;2013;173625.

65. Dewar MJ, Thiel W. Ground states of molecules. 38. The MNDO method. Approximations and parameters. J Am Chem Soc. 1977;99(15):4899-907.

66. Ahamad I, Prasad R, Quraishi M. Experimental and quantum chemical characterization of the adsorption of some Schiff base compounds of phthaloyl thiocarbohydrazide on the mild steel in acid solutions. Mater Chem Phys. 2010;124(2-3):1155-65.

67. Goel R, Siddiqi WA, Ahmed B, Khan MS, Chaubey V. Synthesis characterization and corrosion inhibition efficiency of N-C2 \{(2E)-2-[4-(dimethylamino) benzylidene] hydrazinyl $\}$ 2-oxo ethyl benzamide on mild steel. Desalination. 2010;263(1-3):45-57. 


\section{Supplementary material}

The following online material is available for this article: Supplementary file - Temkin Isotherm. 